\title{
Development of the Drude Polarizable Force Field for DNA and RNA and Applications to Investigations of Nucleic Acid Structure and Dynamics
}

\author{
Justin A. Lemkul \\ Department of Biochemistry, Virginia Tech
}

American Chemical Society National Meeting

Spring 2020 


\section{The Classical Drude Oscillator Model}

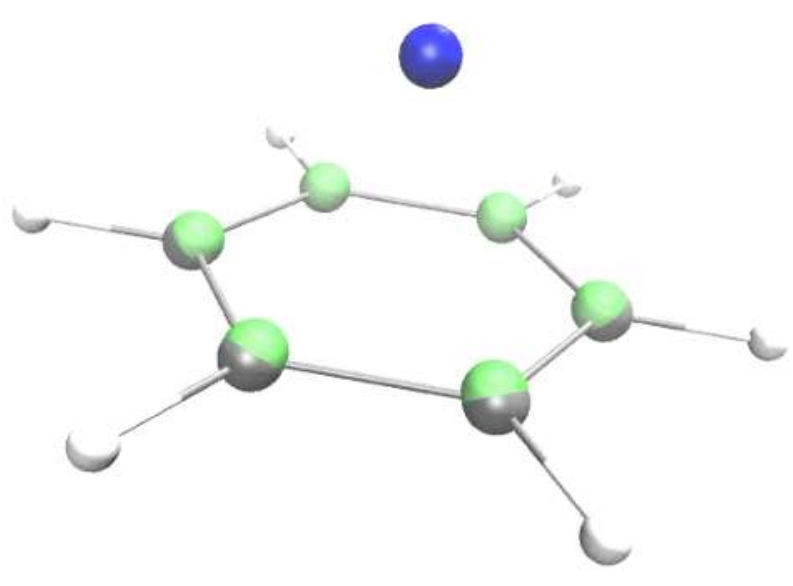

Response to electric field and molecular polarizability
A
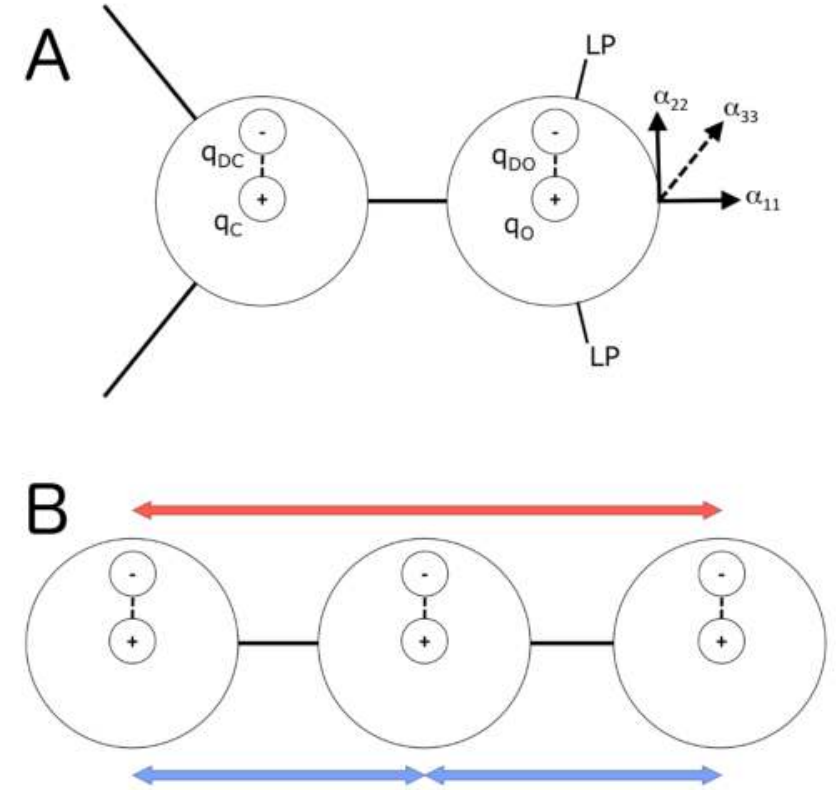

C

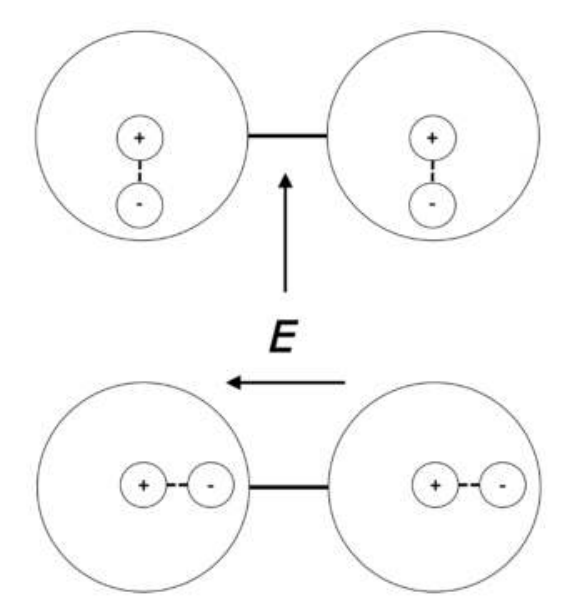

$\alpha=\frac{q_{\mathrm{D}}^{2}}{k_{\mathrm{D}}}$

Neighboring dipole screening

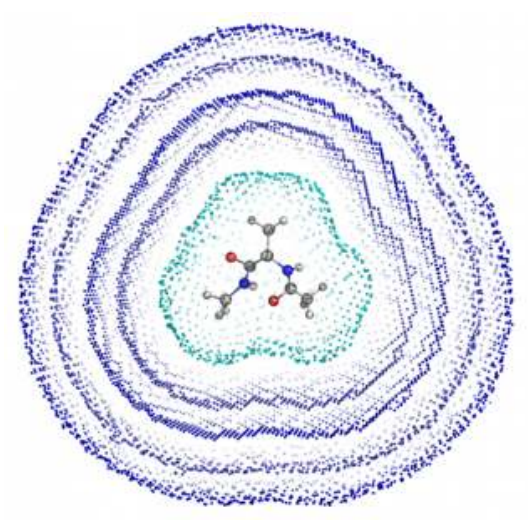




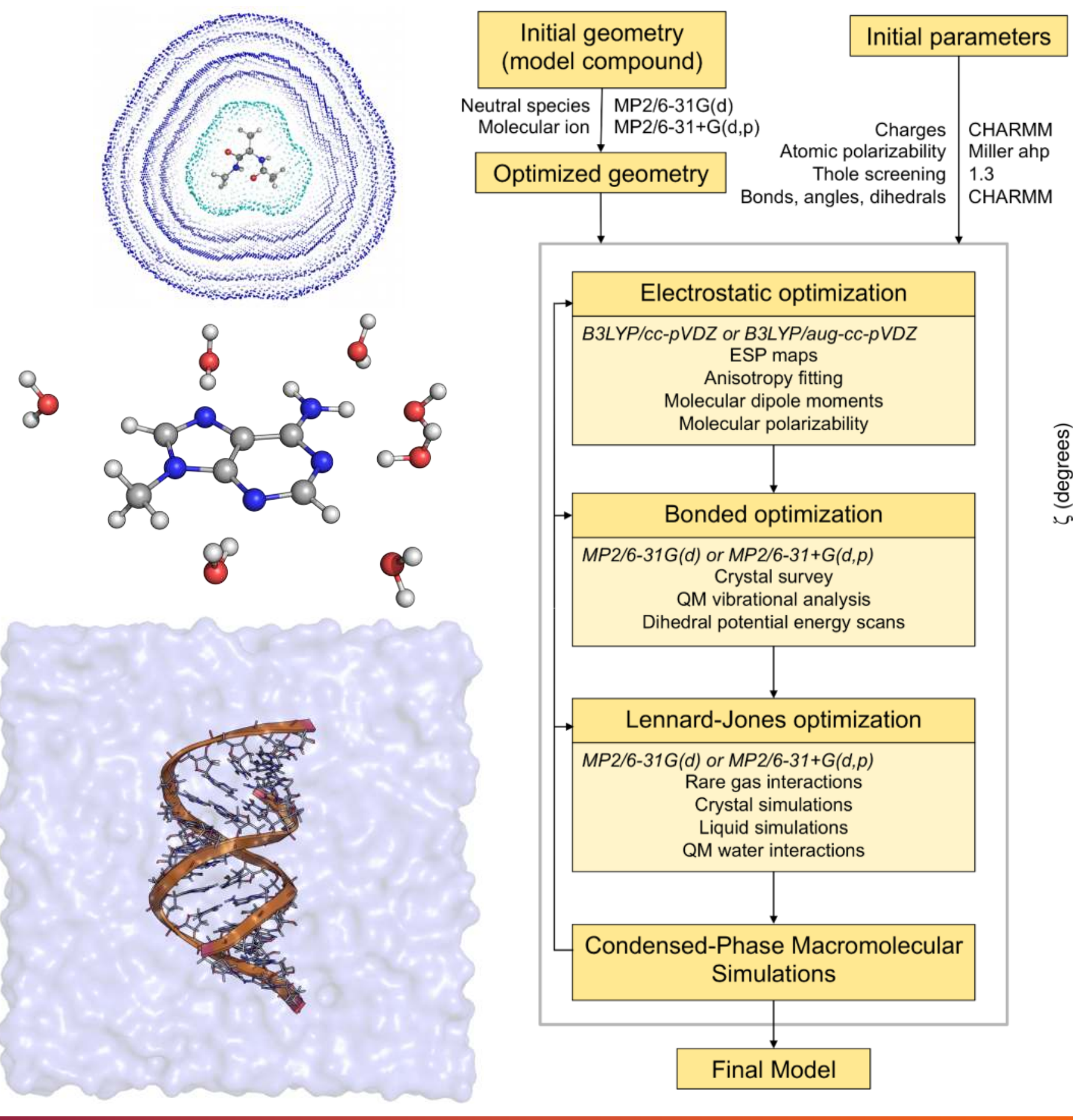

JAL, J. Huang, B. Roux, and A.D. MacKerell Jr. (2016) Chem. Rev. 116: 4983-5013.

V7 VIRGINIA 


\section{DNA Stability with Drude-2013}

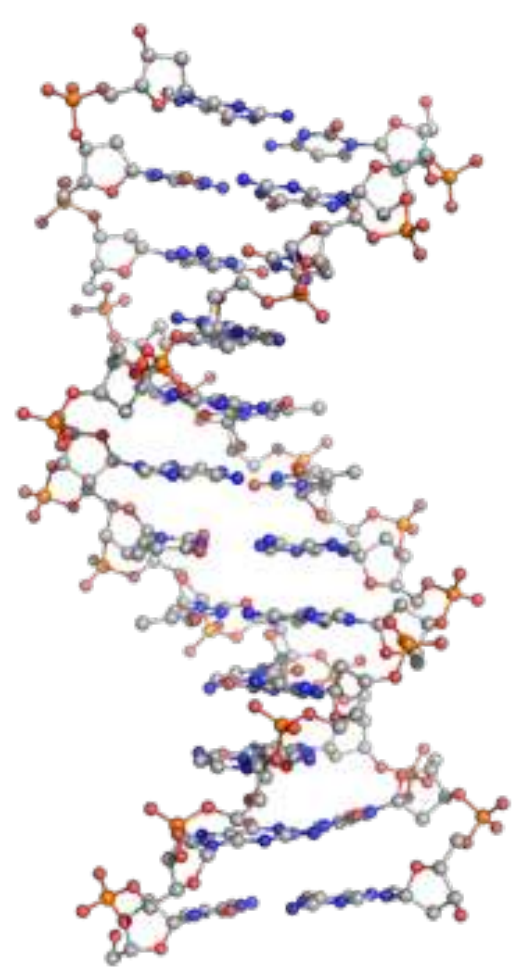

Crystal

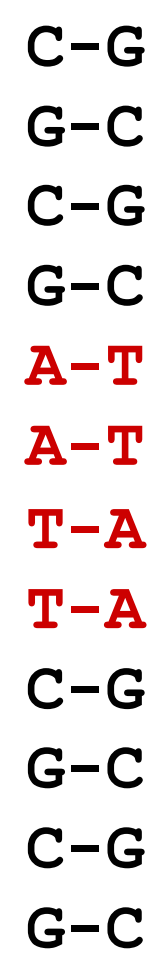

G-C

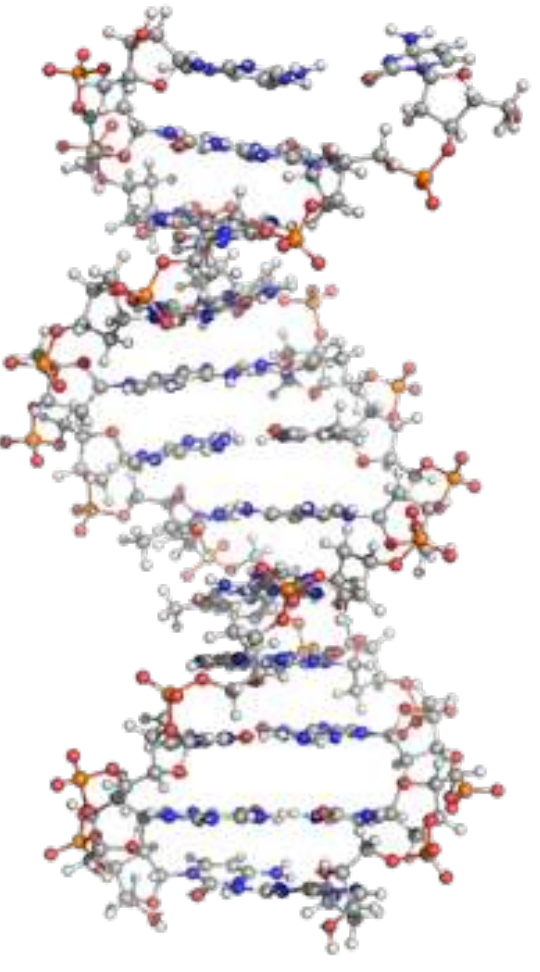

180 ns
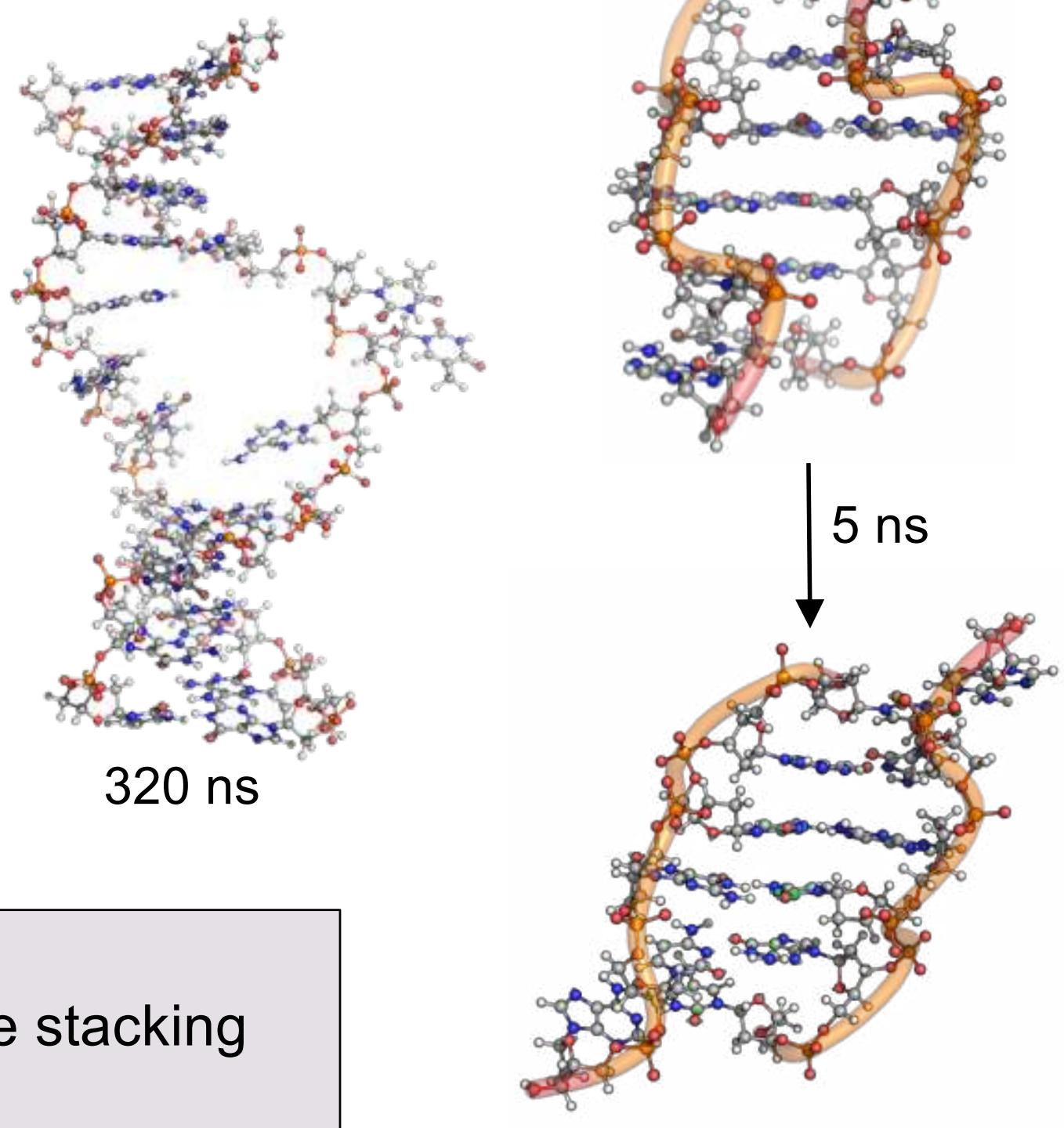

V『 VIRGINIA 


\section{Drude Nucleic Acid Force Field Development}
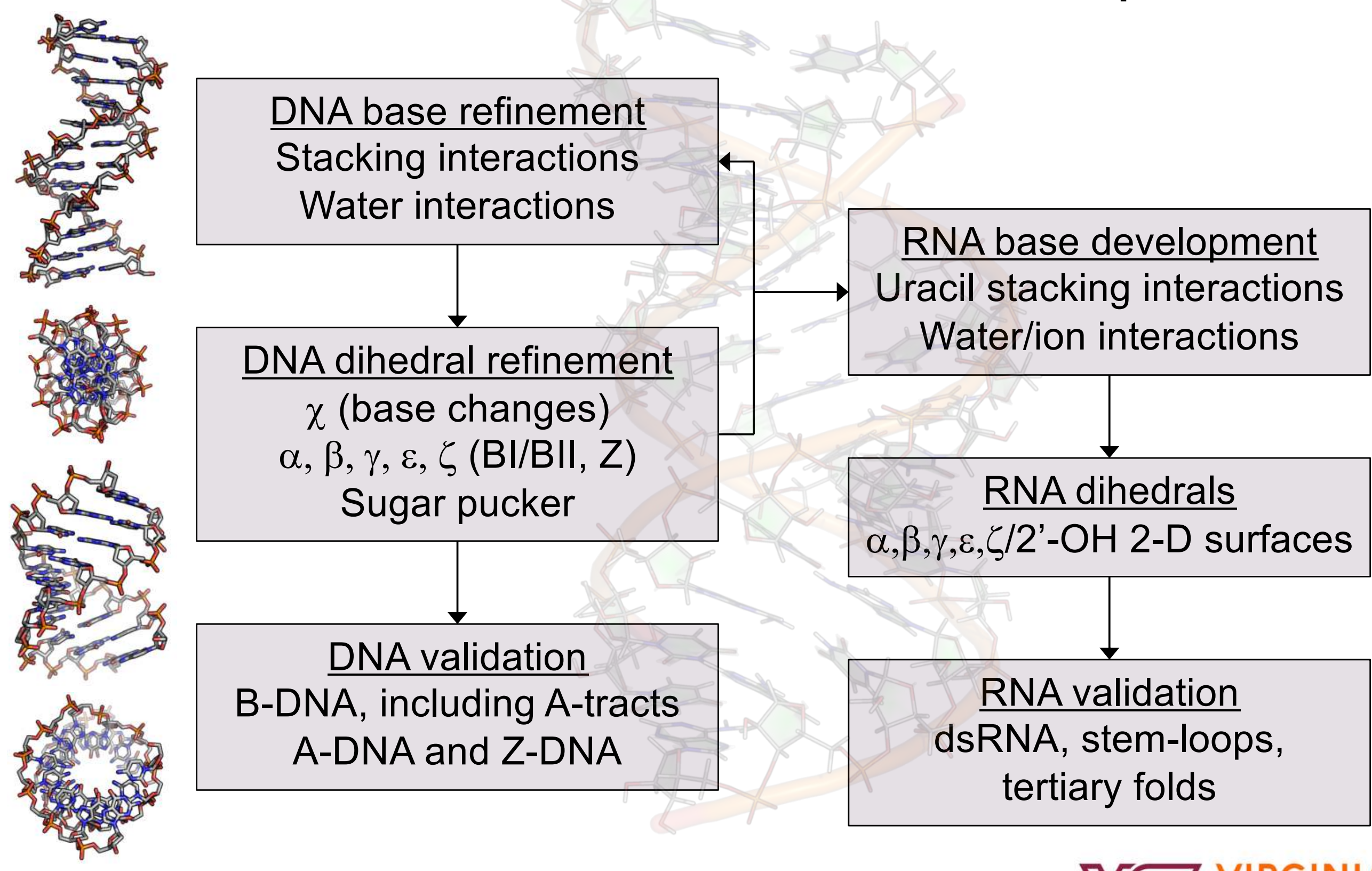


\section{DNA Refinement: Base Stacking}

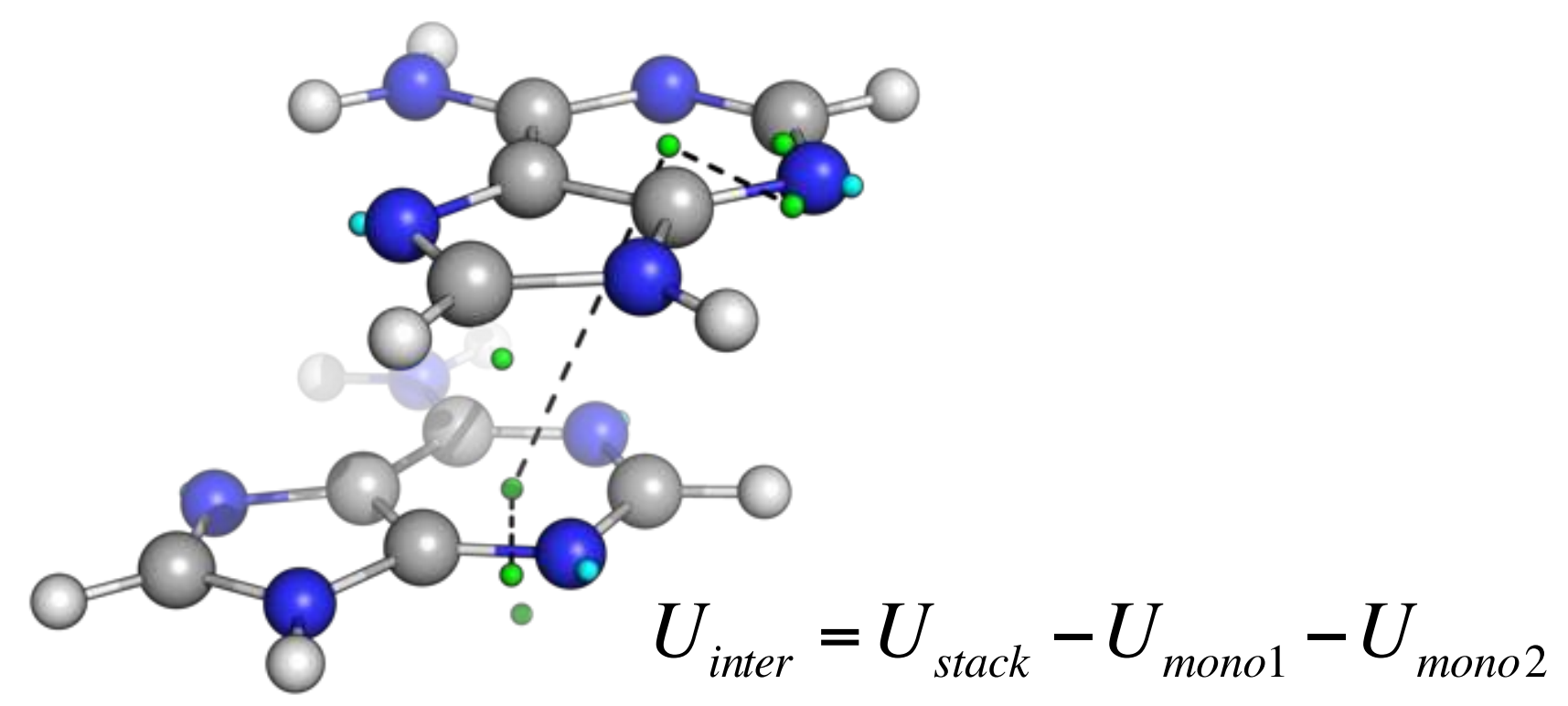

\begin{tabular}{|c|c|c|c|c|c|c|c|c|c|}
\hline & \multicolumn{3}{|c|}{ A-DNA } & \multicolumn{3}{|c|}{ B-DNA } & \multicolumn{3}{|c|}{$\Delta \mathrm{U}_{\text {inter }}(\mathrm{B}-\mathbf{A})$} \\
\hline & C36 & $\begin{array}{c}\text { Drude- } \\
2013\end{array}$ & $\begin{array}{c}\text { Drude- } \\
2017\end{array}$ & C36 & $\begin{array}{c}\text { Drude- } \\
2013\end{array}$ & $\begin{array}{c}\text { Drude- } \\
2017\end{array}$ & C36 & $\begin{array}{c}\text { Drude- } \\
2013\end{array}$ & $\begin{array}{c}\text { Drude- } \\
2017\end{array}$ \\
\hline Avg. Err. & -0.41 & 0.95 & -0.11 & 0.18 & 1.34 & -0.12 & 0.64 & 0.40 & -0.01 \\
\hline AUE & 1.44 & 1.23 & 0.79 & 1.41 & 1.44 & 0.61 & 1.12 & 0.69 & 0.70 \\
\hline RMSE & 1.67 & 1.45 & 0.95 & 1.34 & 1.21 & 0.75 & 1.39 & 0.94 & 0.86 \\
\hline
\end{tabular}




\section{DNA Refinement: Sugar Puckering}
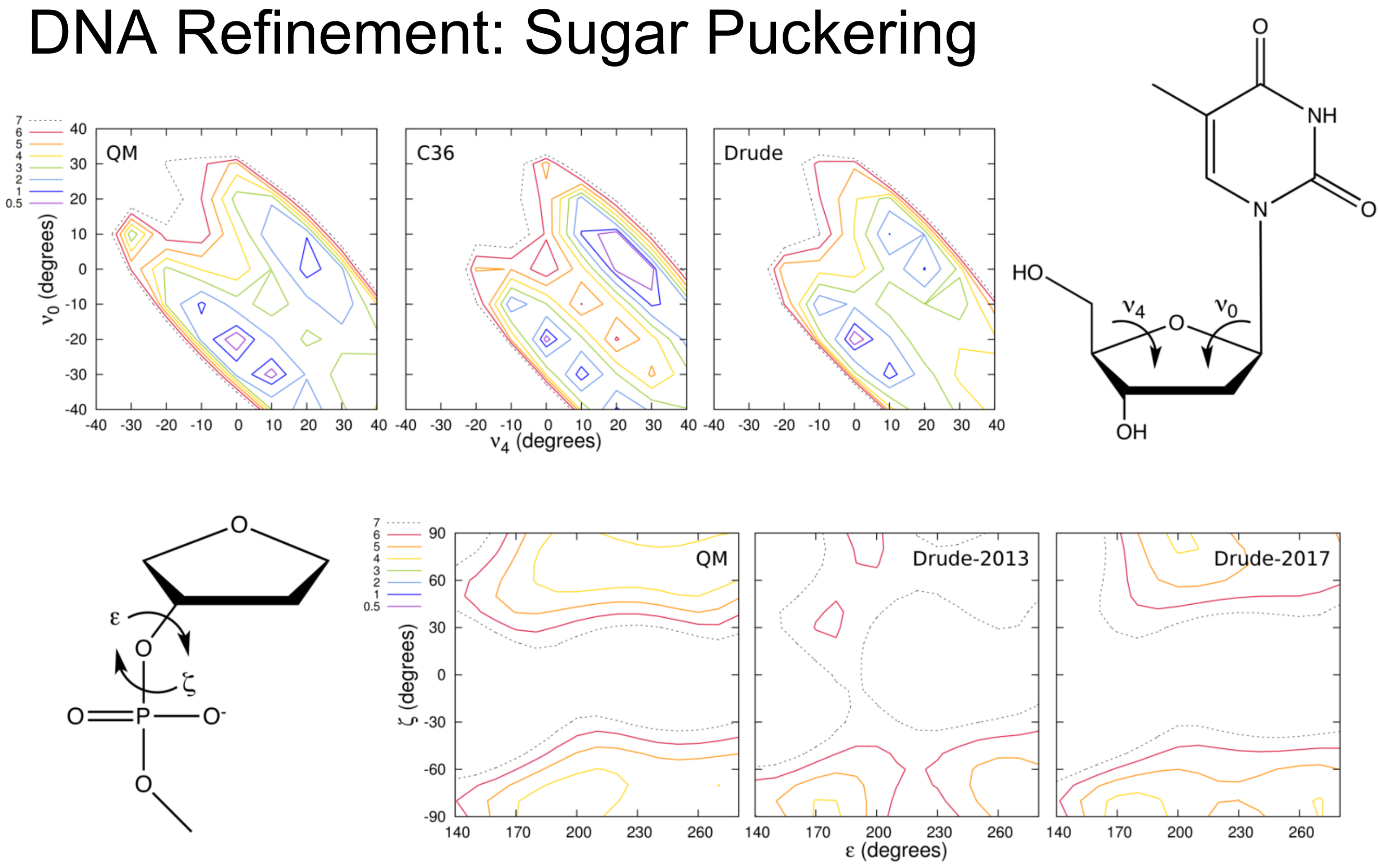

JAL and A.D. MacKerell Jr. JCTC (2017) 13: 2053-2071.

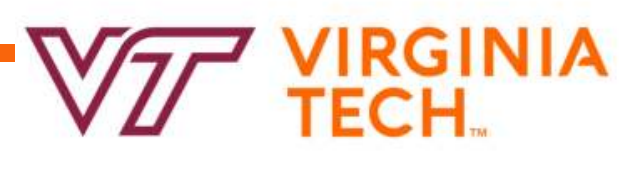




\section{DNA Refinement: Backbone Dihedrals}

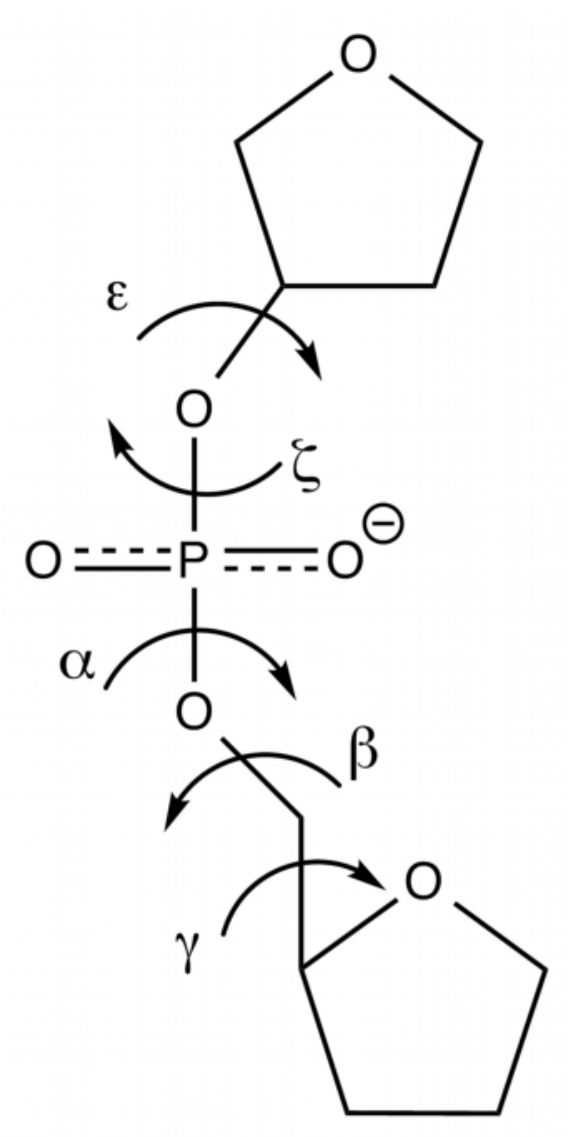

T3PS

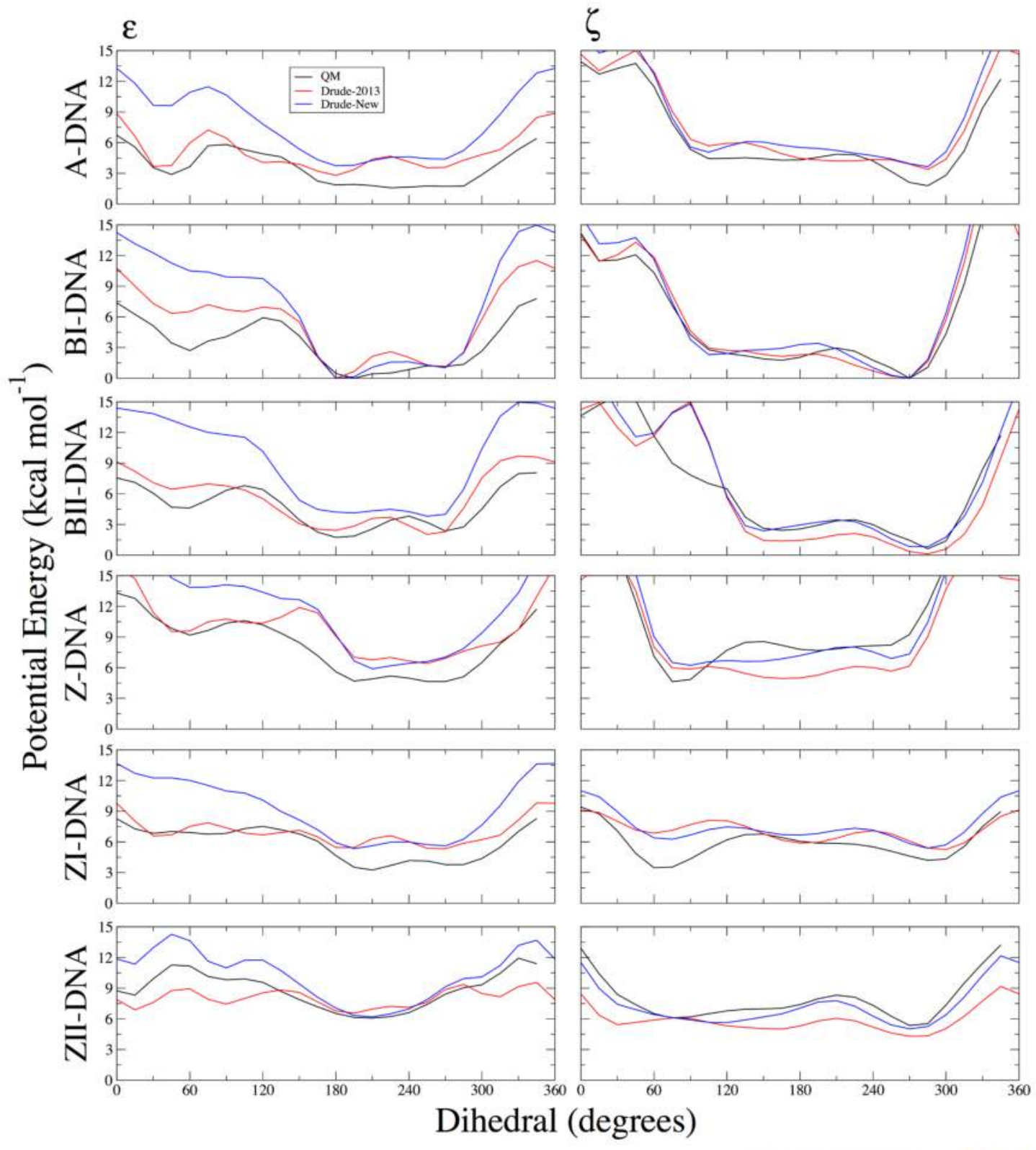

VҐ VIRGINIA 


\section{Drude-2017 B-DNA}

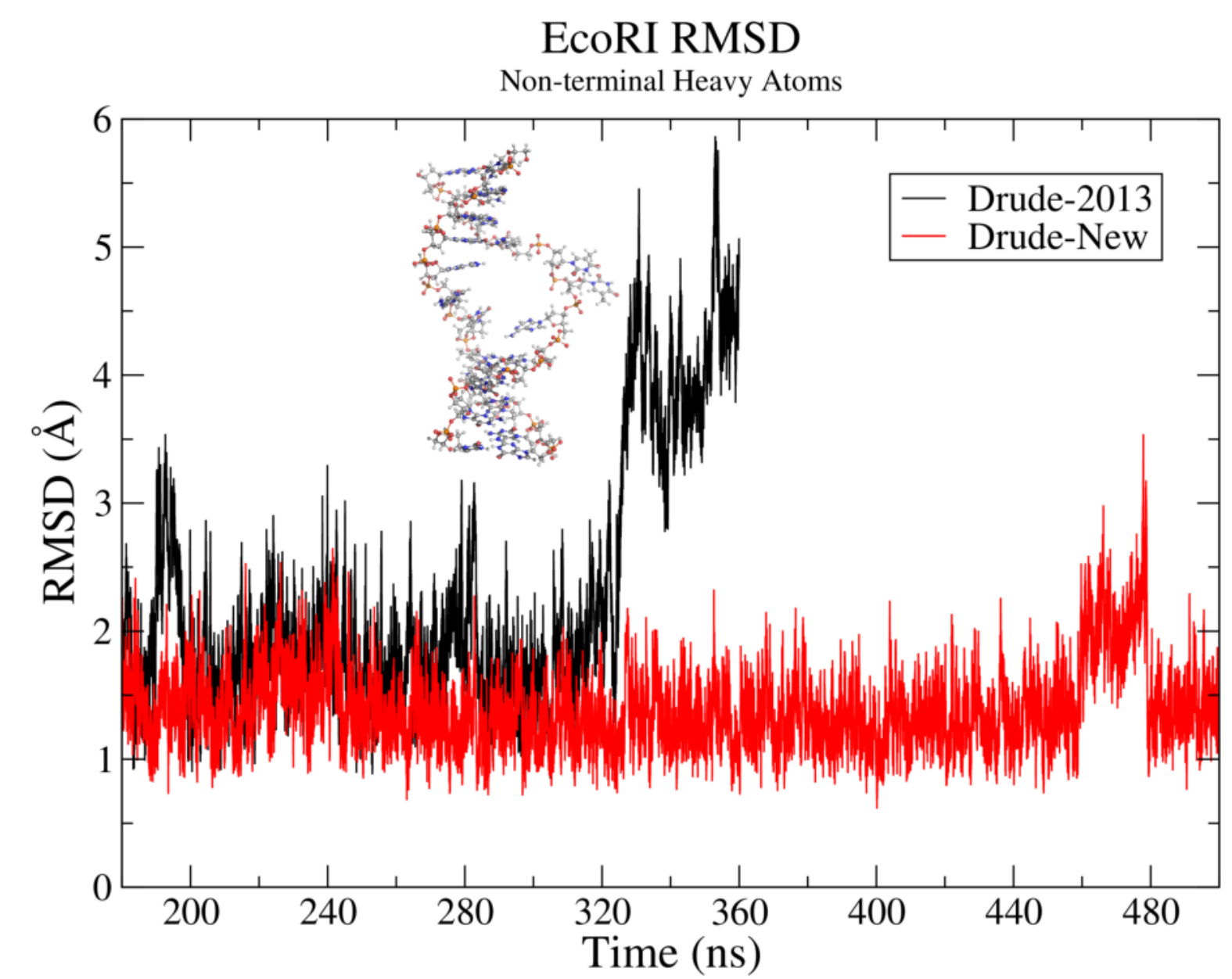

JAL and A.D. MacKerell Jr. JCTC (2017) 13: 2072-2085.
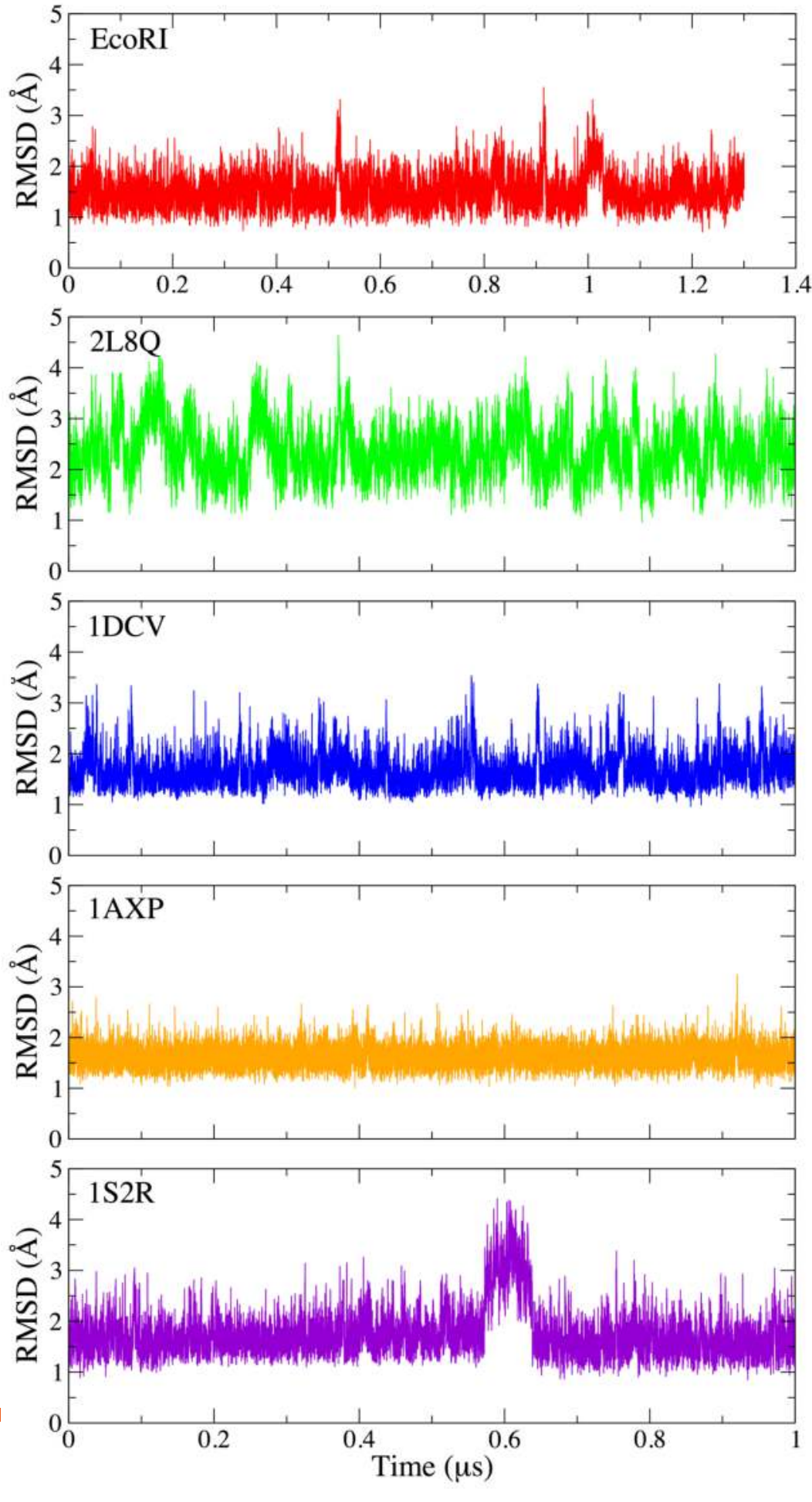


\section{Drude-2017 B-DNA}

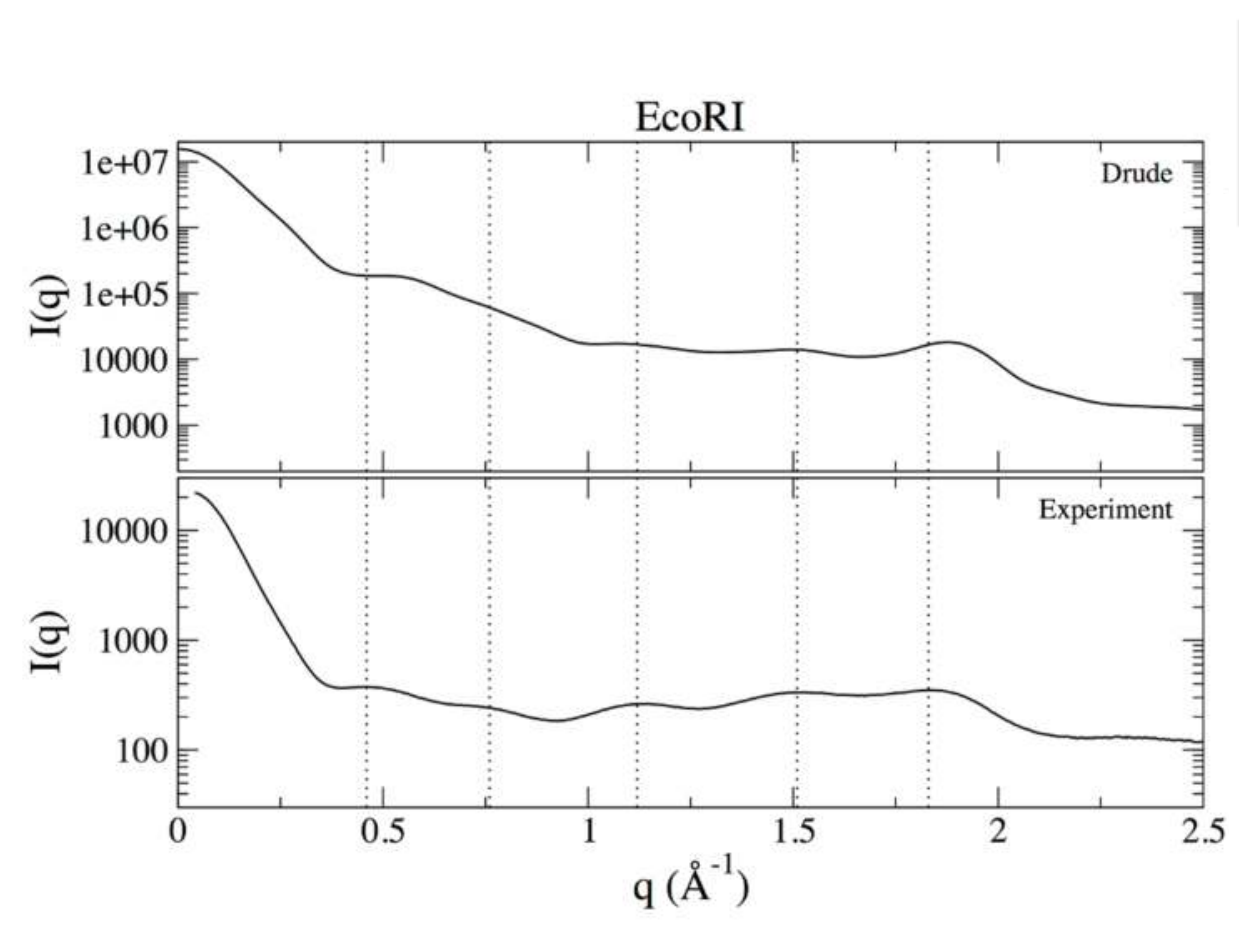

EcoRI $(12 \mathrm{bp})$
P1
P2
P3
P4
P5
1DCV (8 bp)
P1
P2
P3
P4
P5

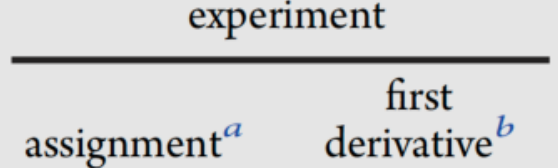

0.48

1.14

1.54

1.87 experiment

0.46

0.76

1.12

1.51

1.83

0.51

0.76

1.18

1.53

1.79
MD simulation

Drude- $2013^{c}$ Drude-new

JAL and A.D. MacKerell Jr. JCTC (2017) 13: 2072-2085. 


\section{Drude-2017 A-DNA}
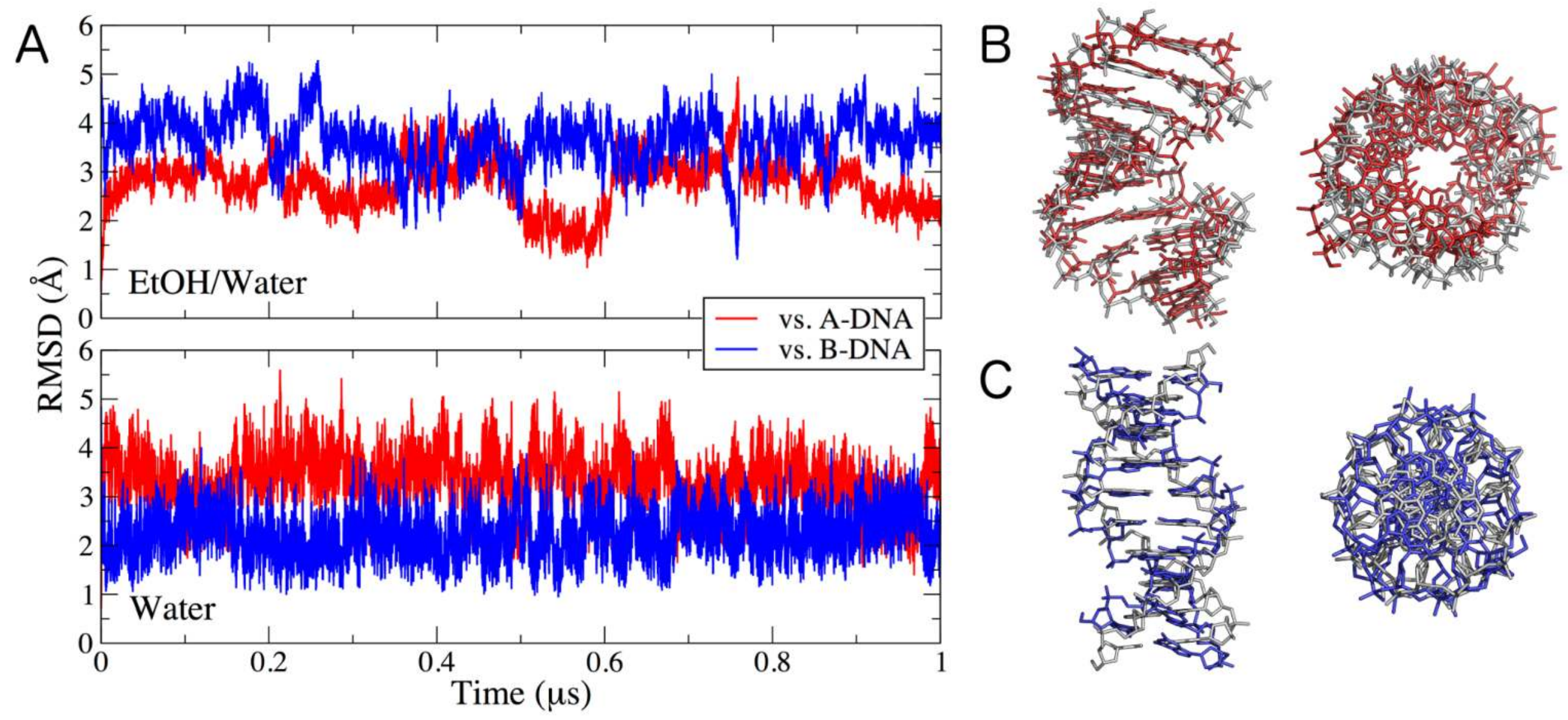

$\mathrm{A} \rightarrow \mathrm{B}$ conversion in water
$\mathrm{A}-\mathrm{DNA}$ stable in $75 \% \mathrm{EtOH}$

JAL and A.D. MacKerell Jr. JCTC (2017) 13: 2072-2085. 


\section{Drude-2017 Z-DNA}
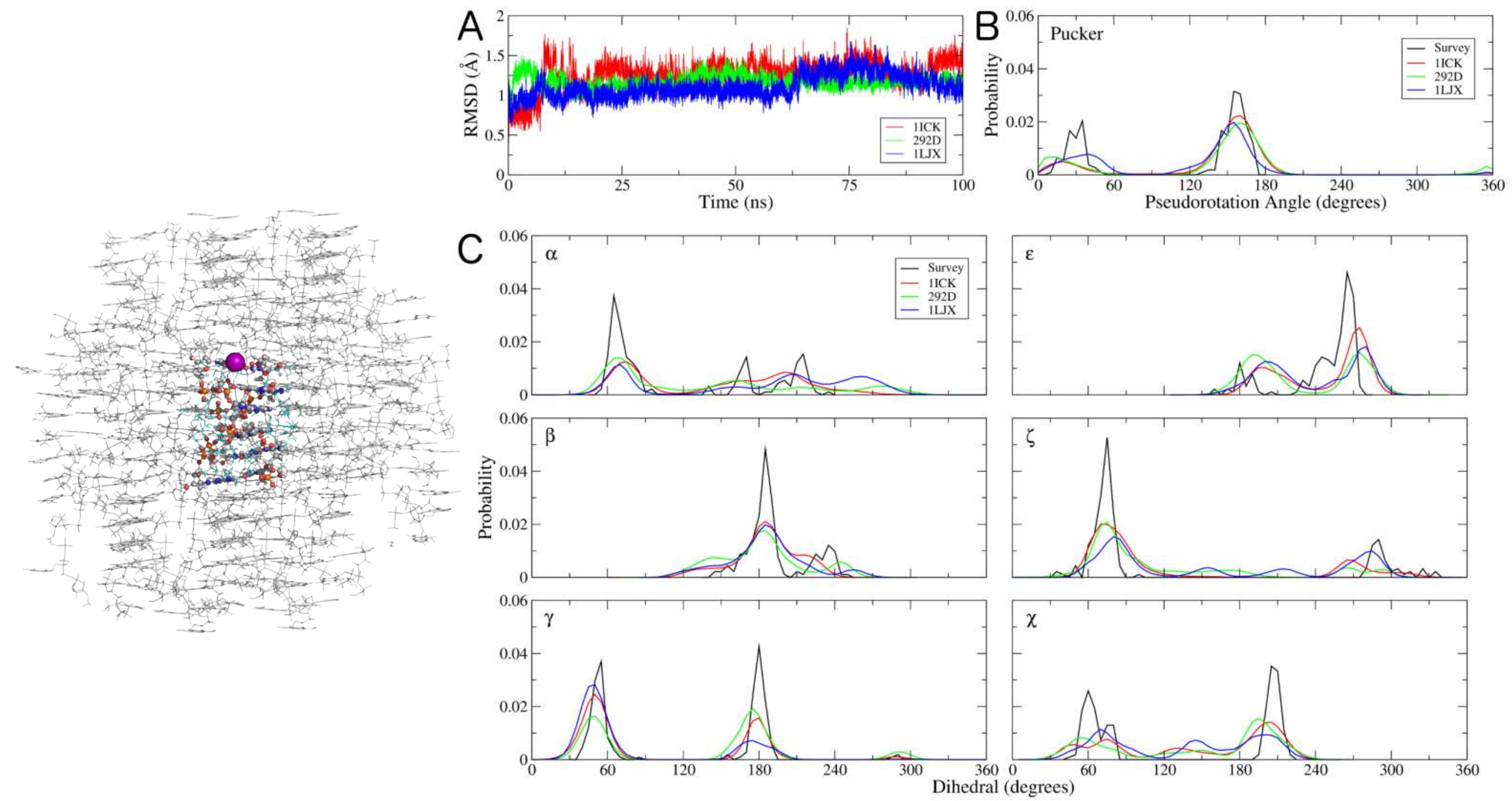

JAL and A.D. MacKerell Jr. JCTC (2017) 13: 2072-2085. 


\section{RNA 2'-OH and Conformational Energetics}
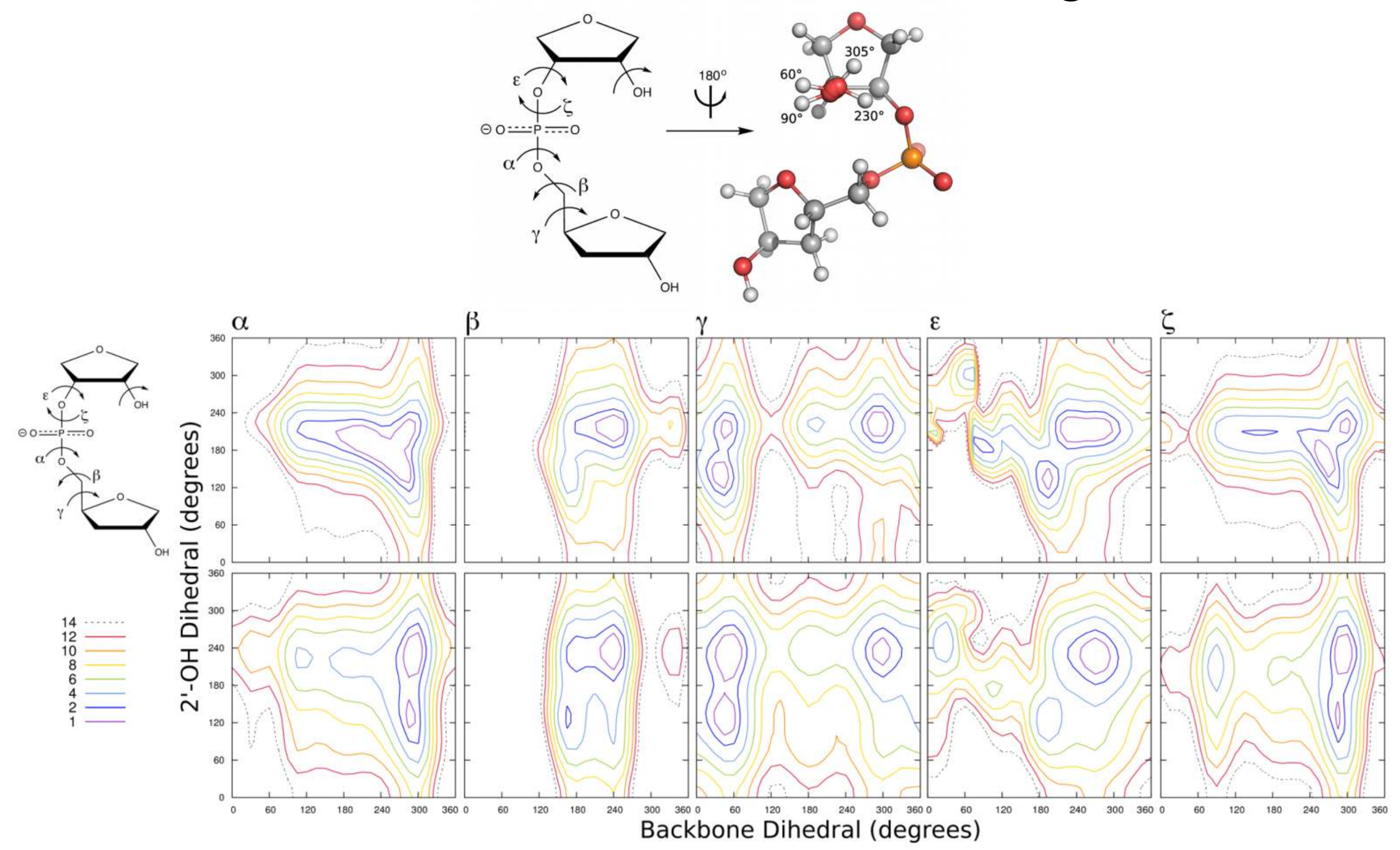

JAL and A.D. MacKerell Jr. JCC (2018) 39: 2624-2646.

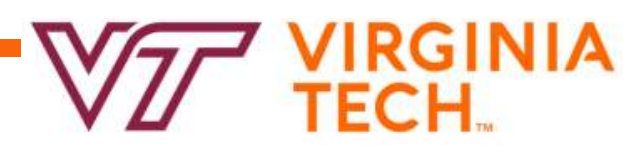




\section{Drude-2017 dsRNA}
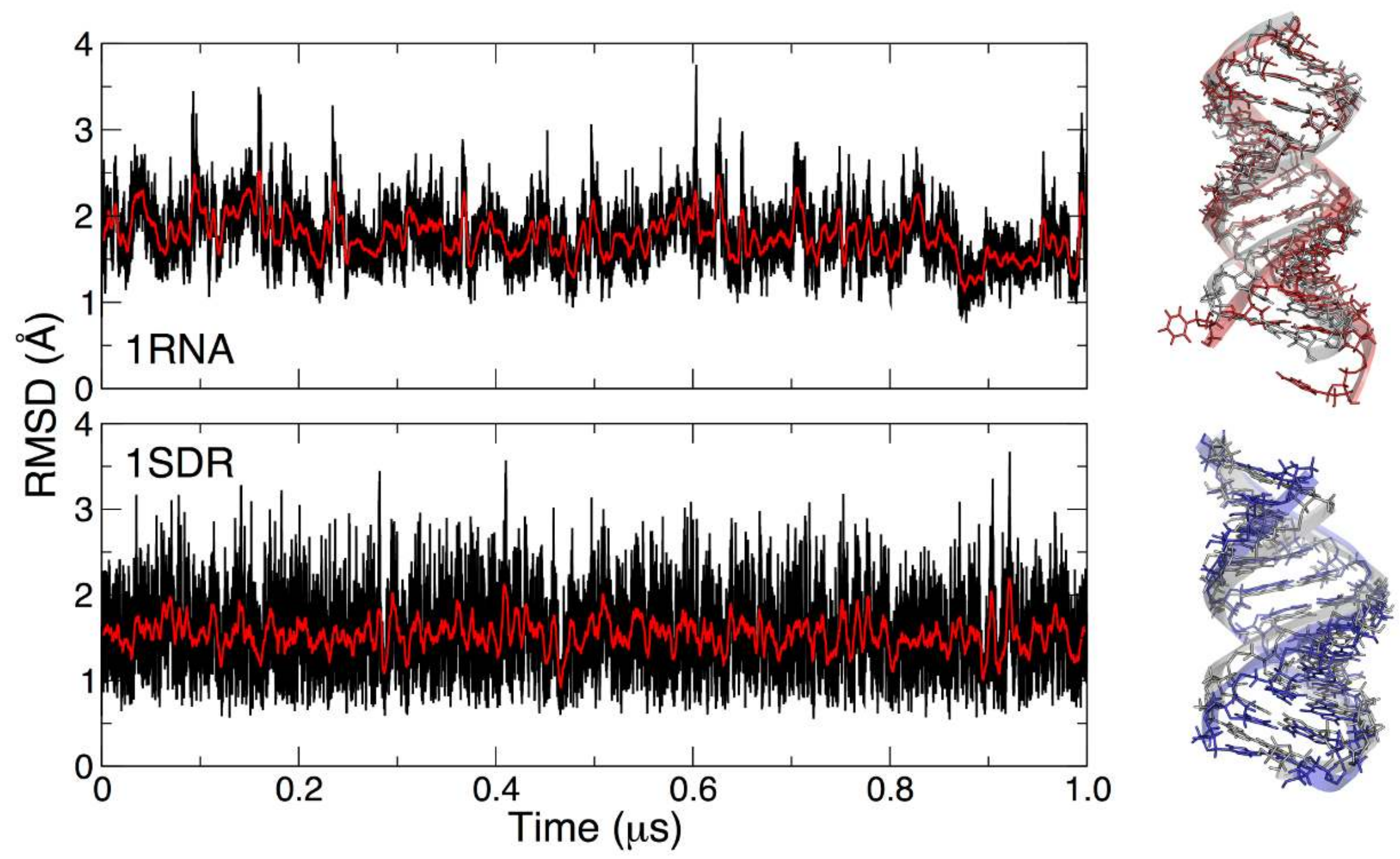


\section{Drude-2017 dsRNA}
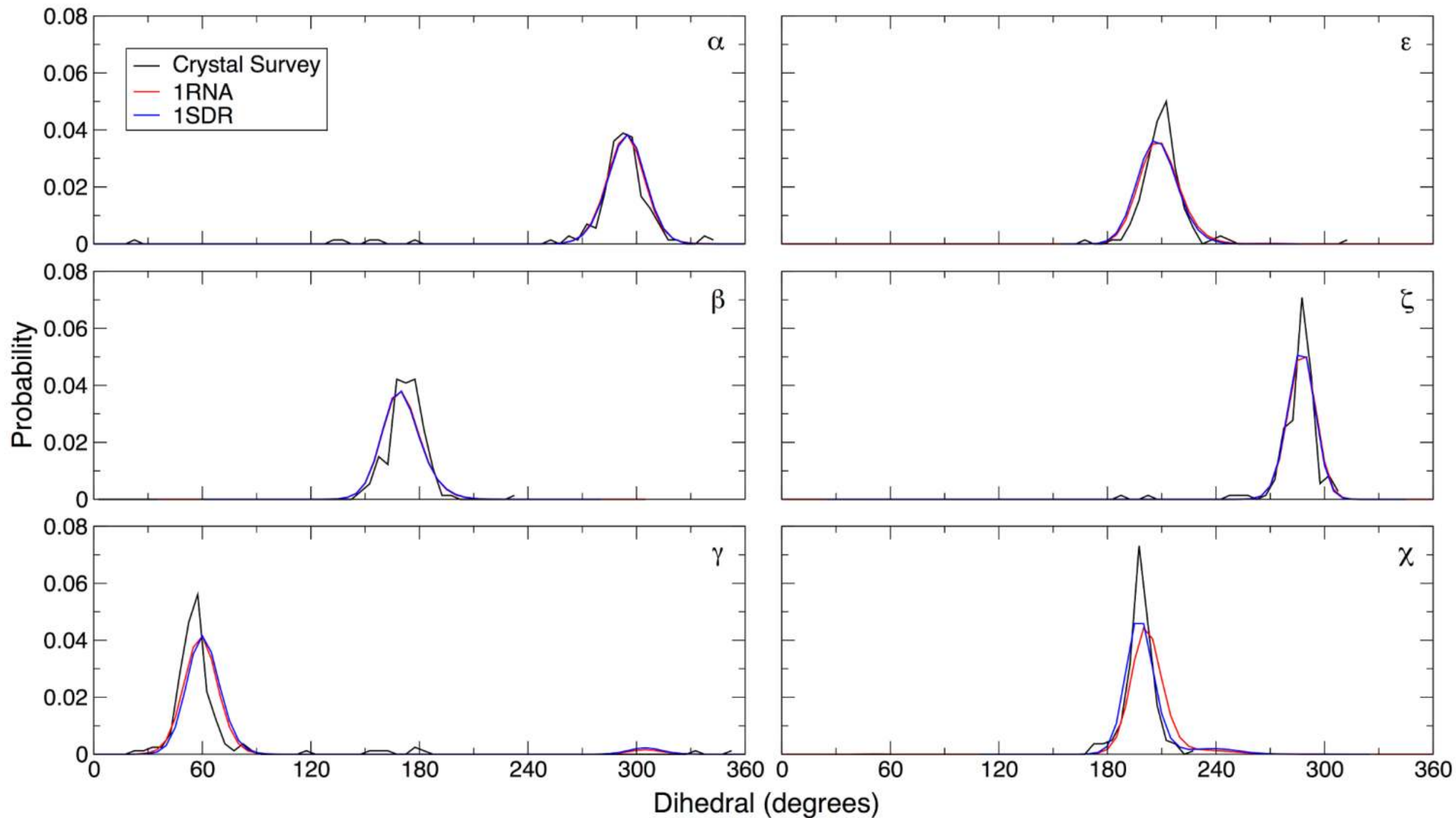

JAL and A.D. MacKerell Jr. JCC (2018) 39: 2624-2646. 


\title{
UUCG Stem-Loop
}

\section{r(GGCACUUCGGUGCC)}

\author{
2KOC Heavy Atom RMSD
}
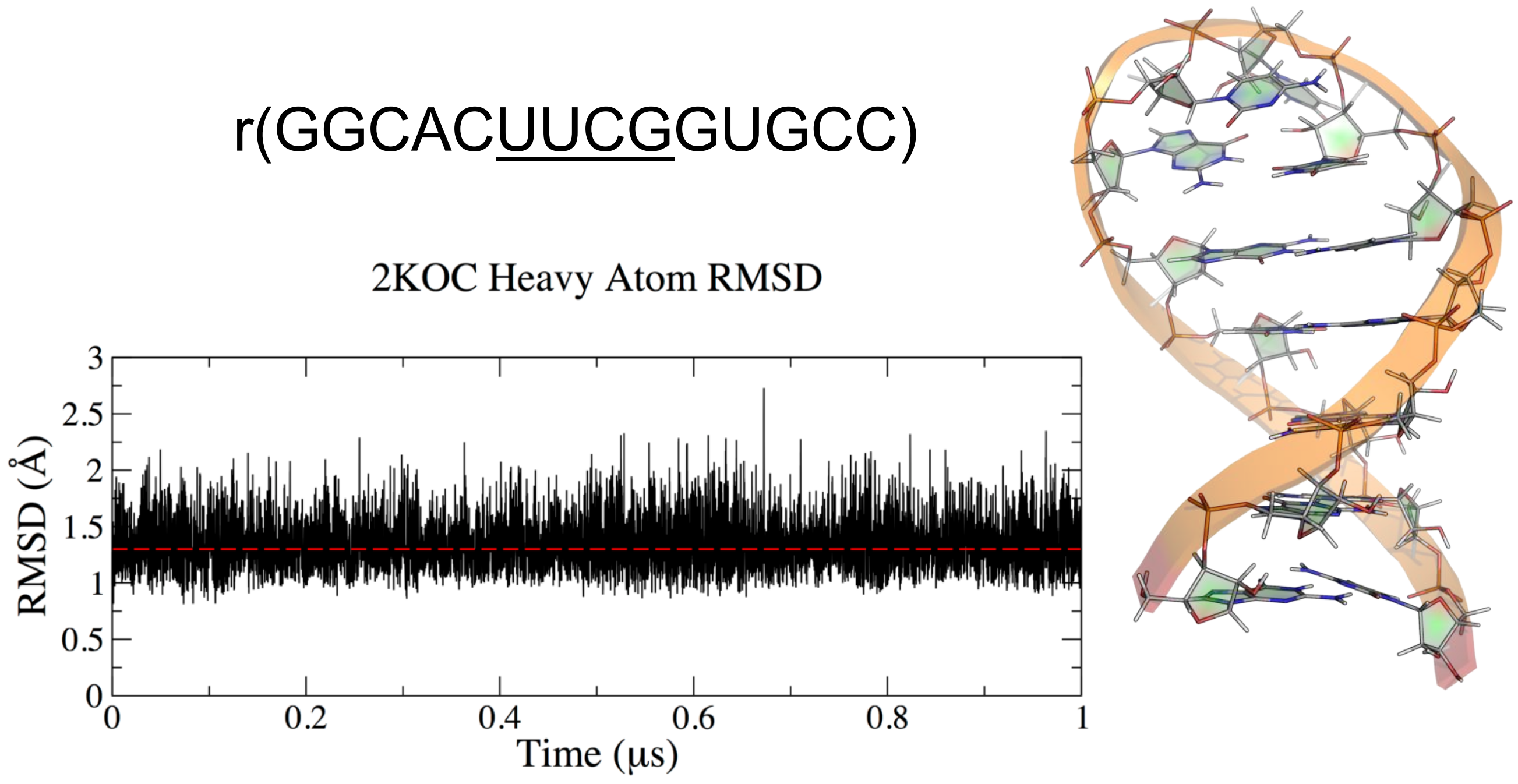


\section{UUCG Stem-Loop}
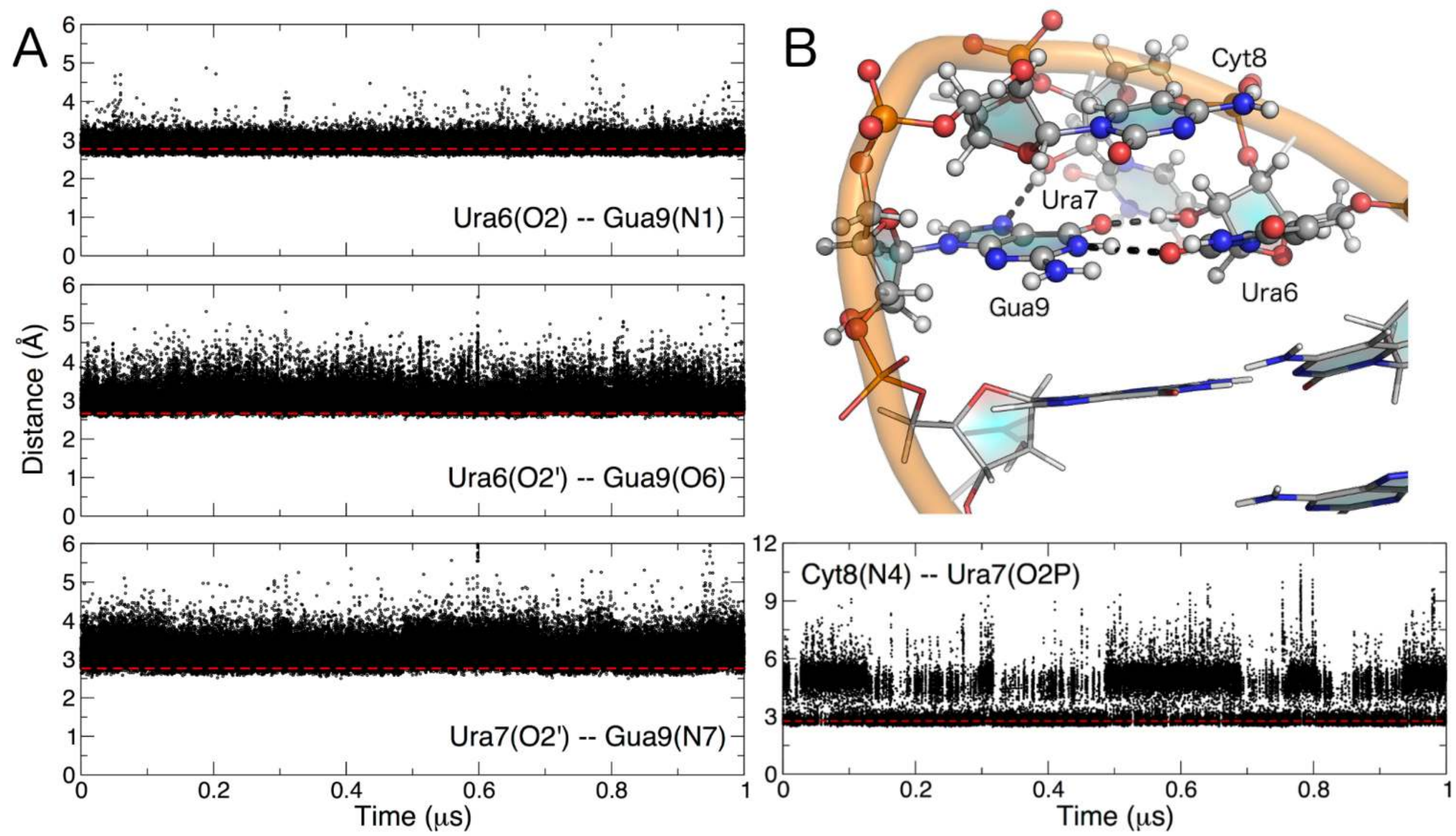

JAL and A.D. MacKerell Jr. JCC (2018) 39: 2624-2646. 


\section{Base Dipole Moments in Stem-Loops}

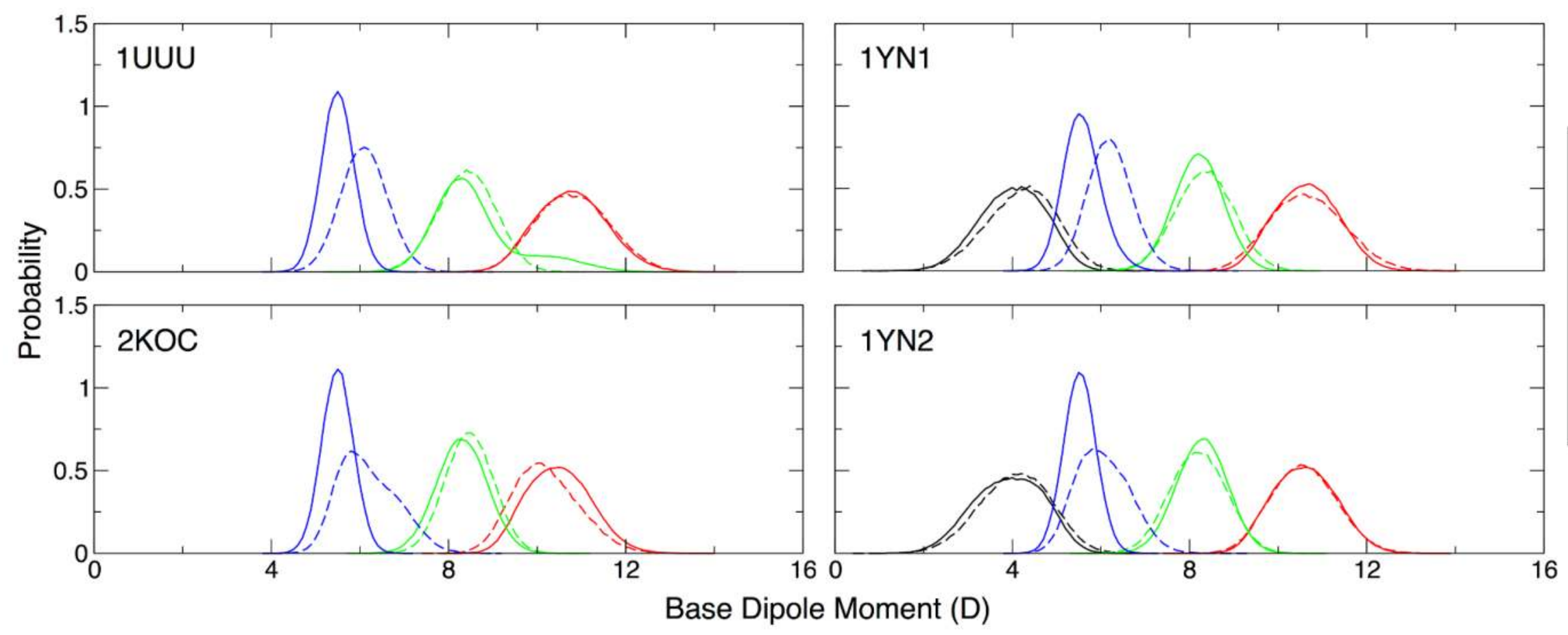

- Ade, Stem

--. Ade, Loop

- Cyt, Stem

-.- Cyt, Loop

- Gua, Stem

-.. Gua, Loop

- Ura, Stem

-.- Ura, Loop

\section{Ade and Ura very sensitive to environment Gua and Cyt less sensitive}




\section{A Brief Foray into $\mathrm{Mg}^{2+}$}
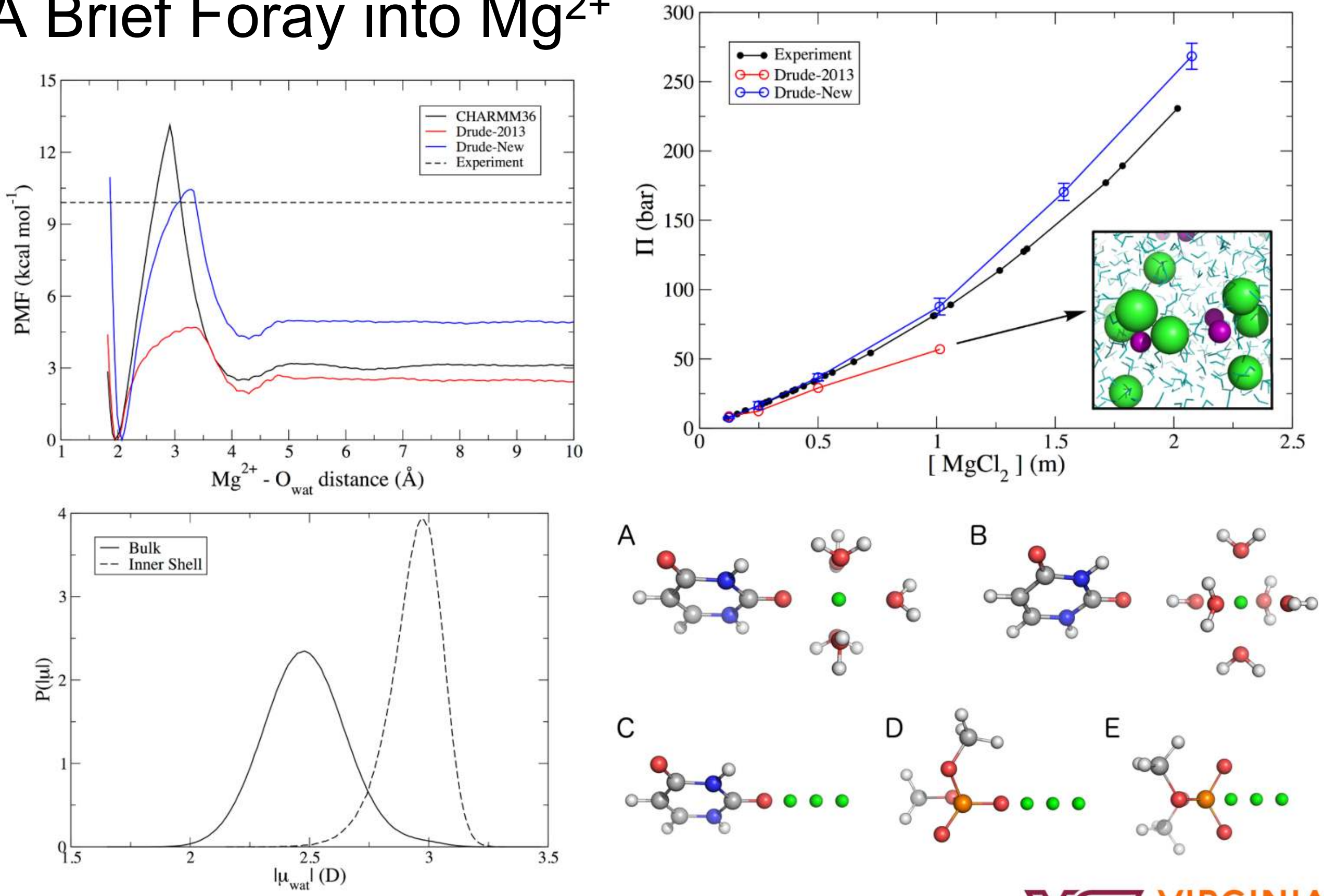

C

$-\frac{9}{0-9}-0.0$

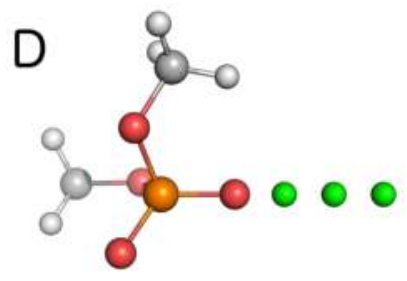

E

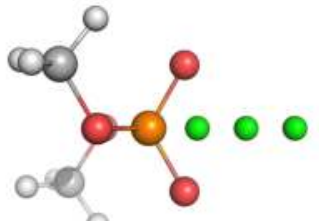

V

VIRGINIA

JAL and A.D. MacKerell Jr. JPCB (2016) 120: 11436-11448. $\mathrm{TECH}_{\mathrm{w}}$ 


\section{The Drude-2017 Nucleic Acid Force Field}

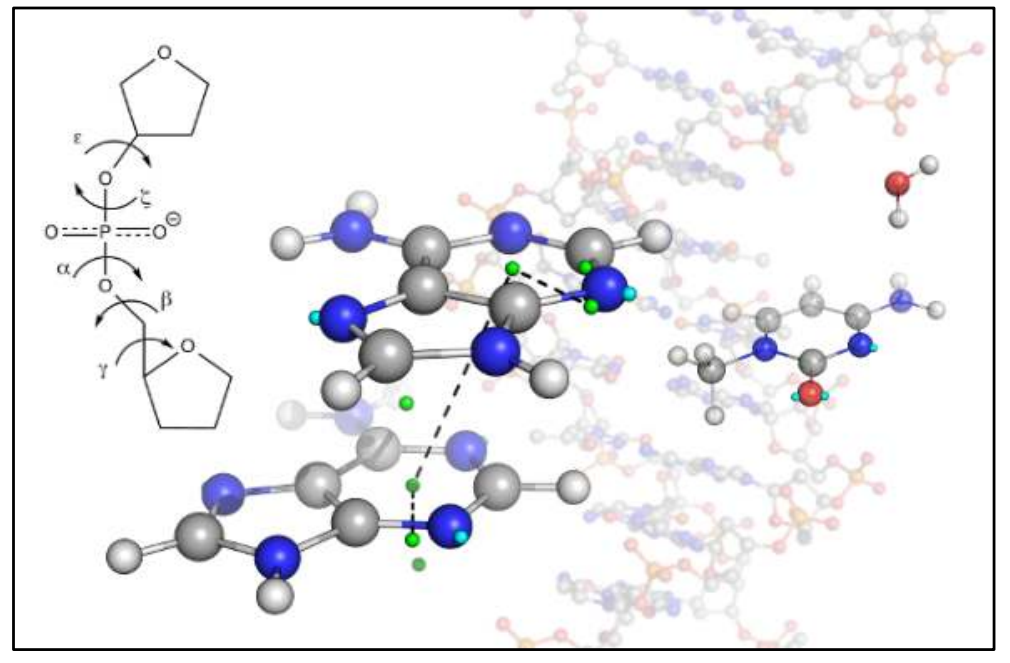

JCTC (2017) 13: 2053-2071

JCTC (2017) 13: 2072-2085

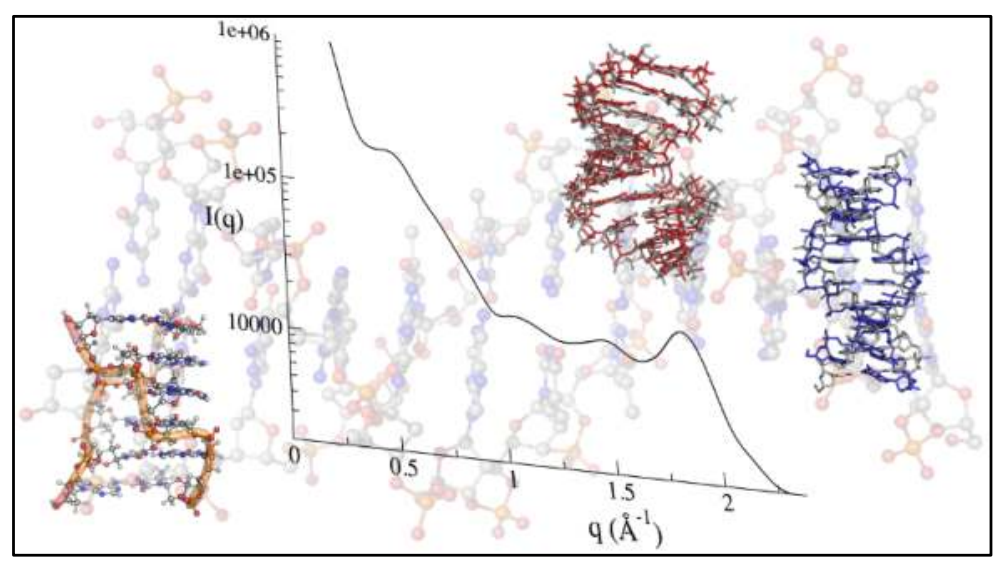

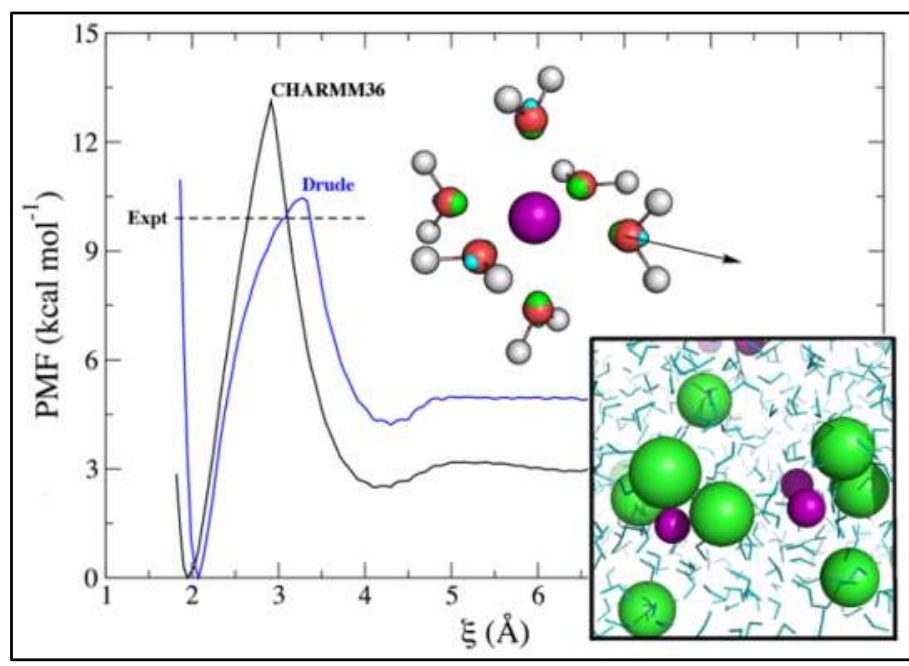

JPCB (2016) 120: 11436-11448

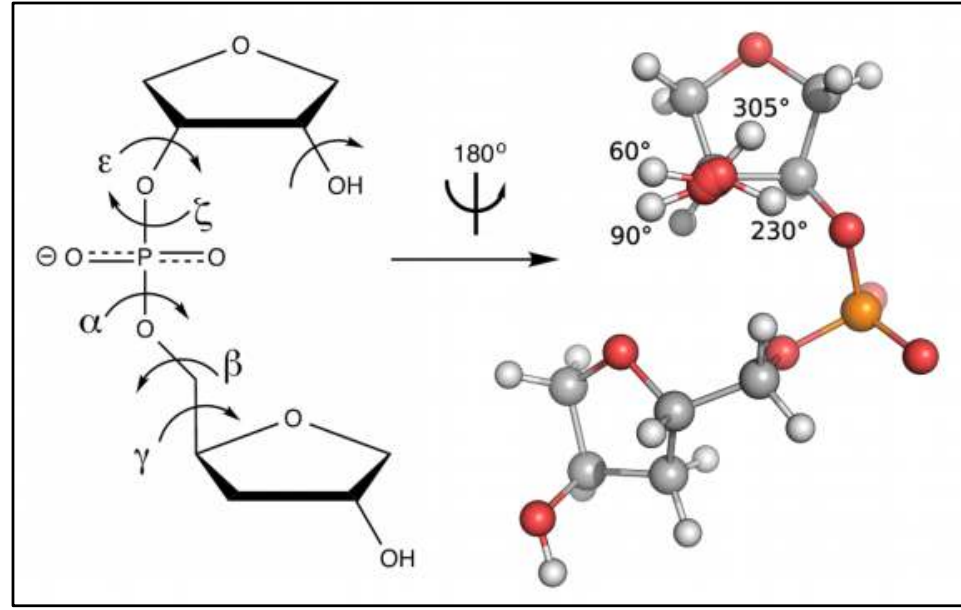

JCC (2018) 39: 2624-2646 


\section{G-Quadruplexes in Biology}
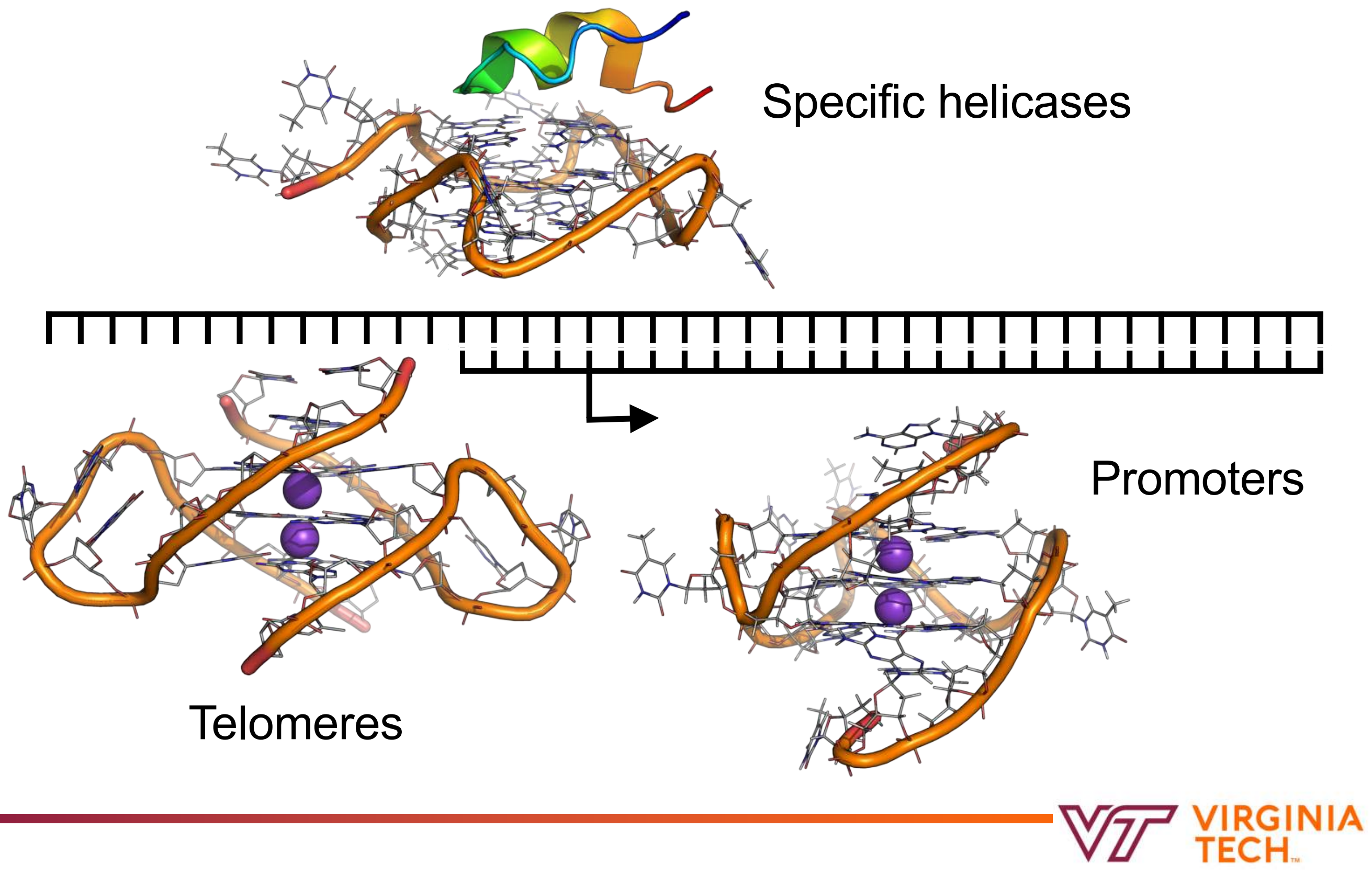


\section{G-Quadruplex Structure}
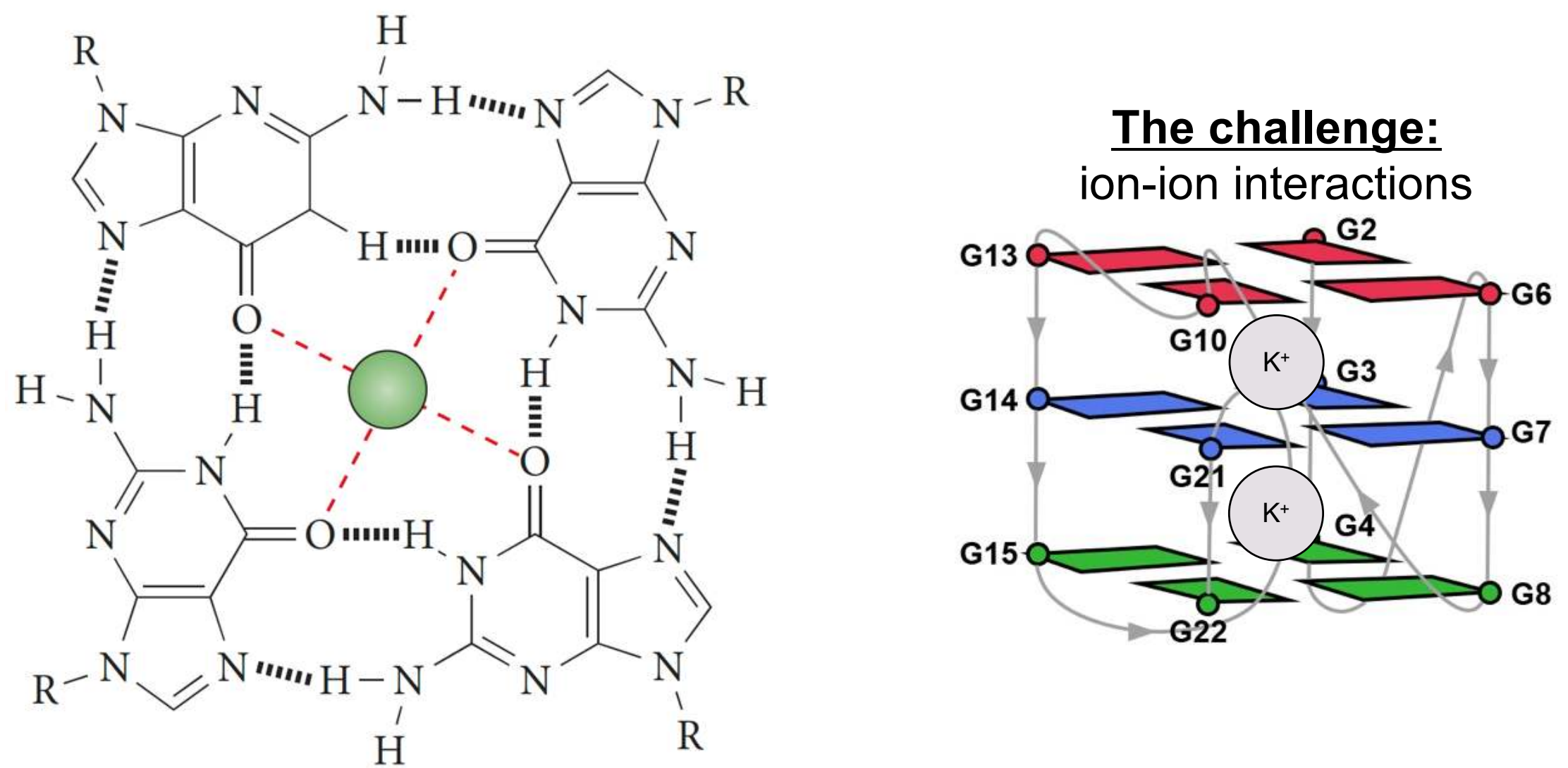

S. Balasubramanian et al. (2011) Nat. Rev. Drug Discov. 10: 261-275. 


\section{Stability of c-kit1 with Drude-2017}
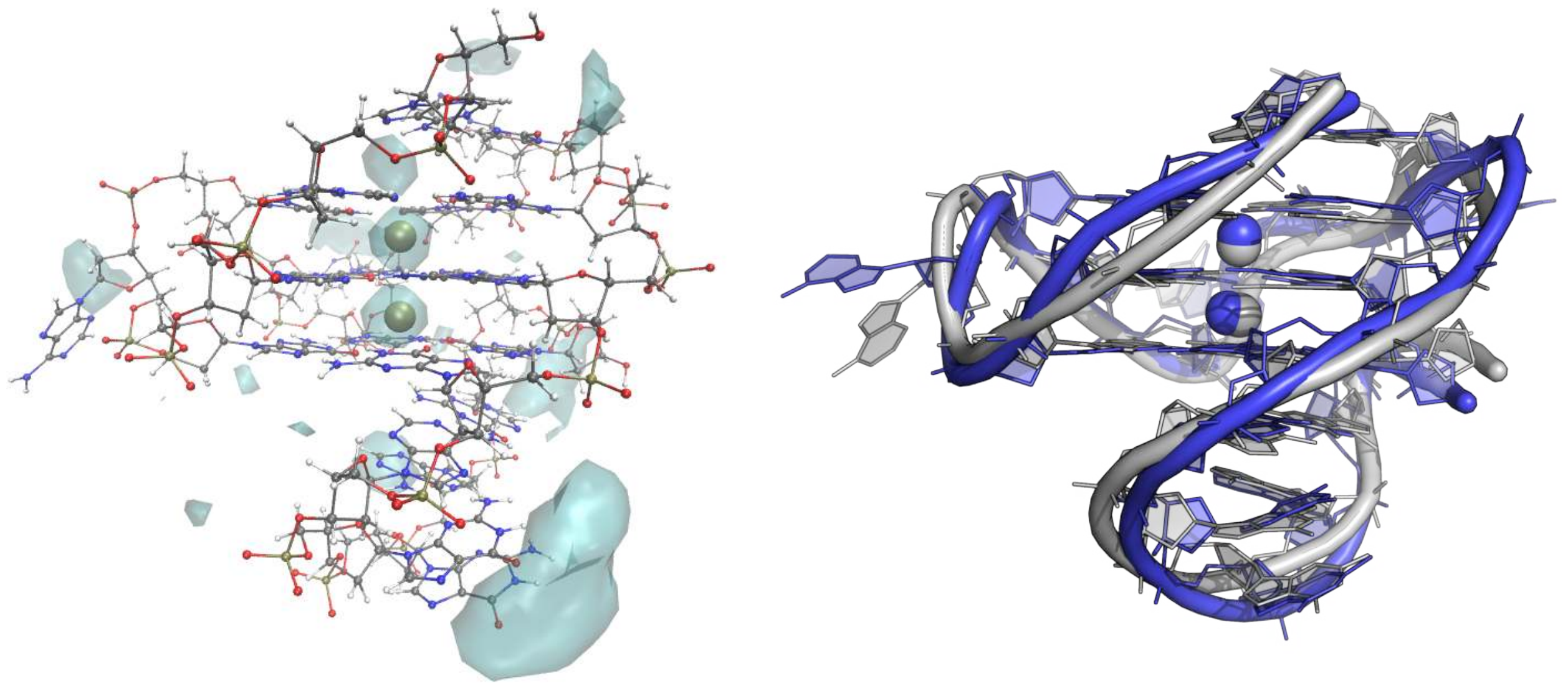

A.M. Salsbury and JAL (2019) JPCB 123 (1): 148-159. 


\section{$\mathrm{K}^{+}$Binding is Cooperative}
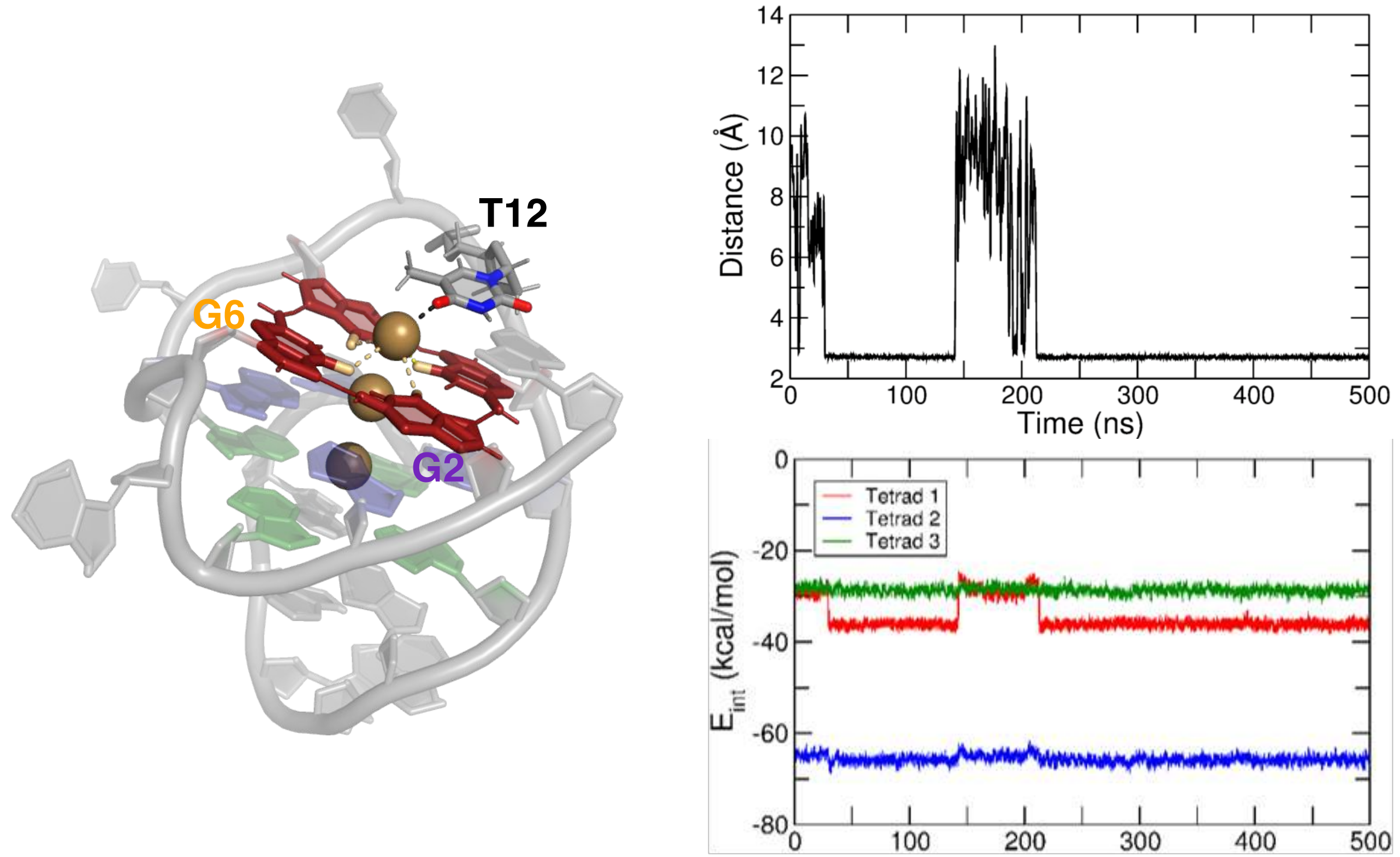

A.M. Salsbury and JAL (2019) JPCB 123 (1): 148-159. 


\section{Electronic Structure of $c-k i t 1$ Stem}
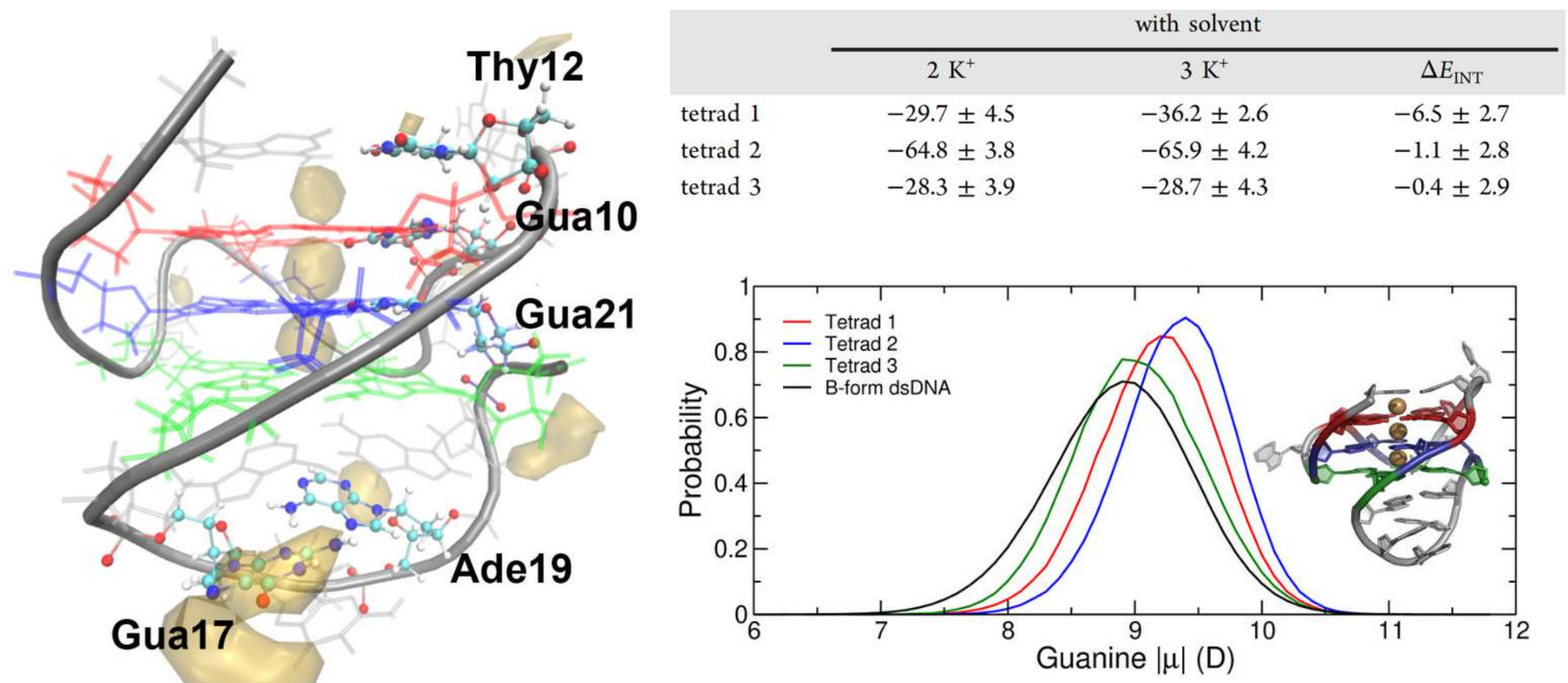

A.M. Salsbury and JAL (2019) JPCB 123 (1): 148-159. 


\section{Nucleobase Dipole Moments in DNA}

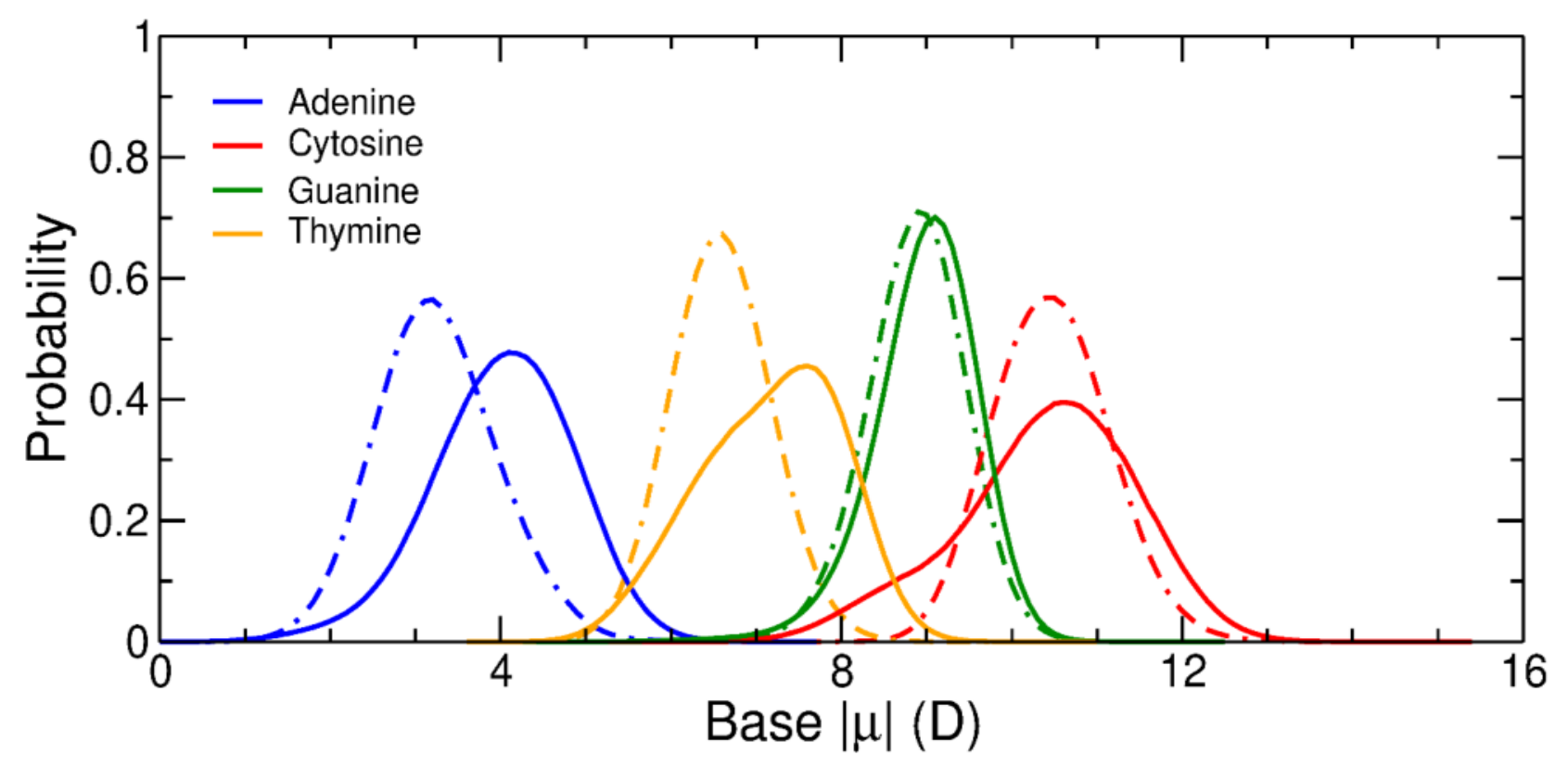

Canonical B-form dsDNA (6 $\mu \mathrm{s})$

1BNA (EcoRI/DD 12mer)

2L8Q (11mer)

1S2R (12mer, A-tract)

1DCV (10mer)

1AXP (purine-rich 10mer)

1ZF1 (10mer)

DNA G-Quadruplexes (20 $\mu \mathrm{s})$

c-kit1: PDB 2O3M $c-k i t 2:$ PDB 2KYP $b c /-2:$ PDB 2F8U $c-m y c:$ PDB 1XAV telomere: PDB 1K8P

JCTC (2017) 13: 2072-2085 


\section{Telomeric GQ Base Dipole Moments}

A

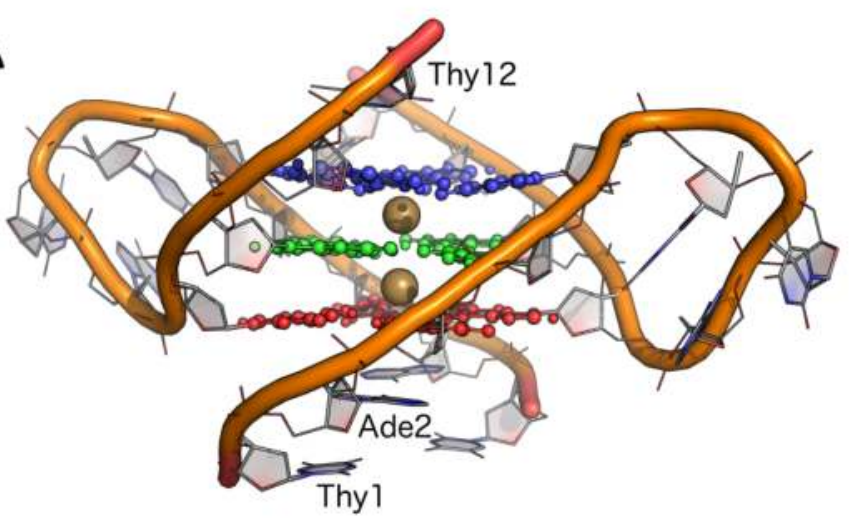

B

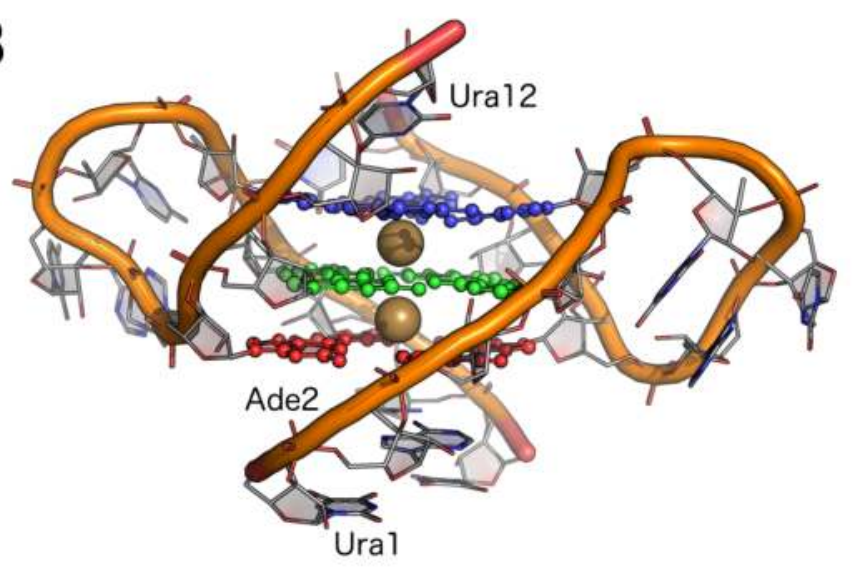

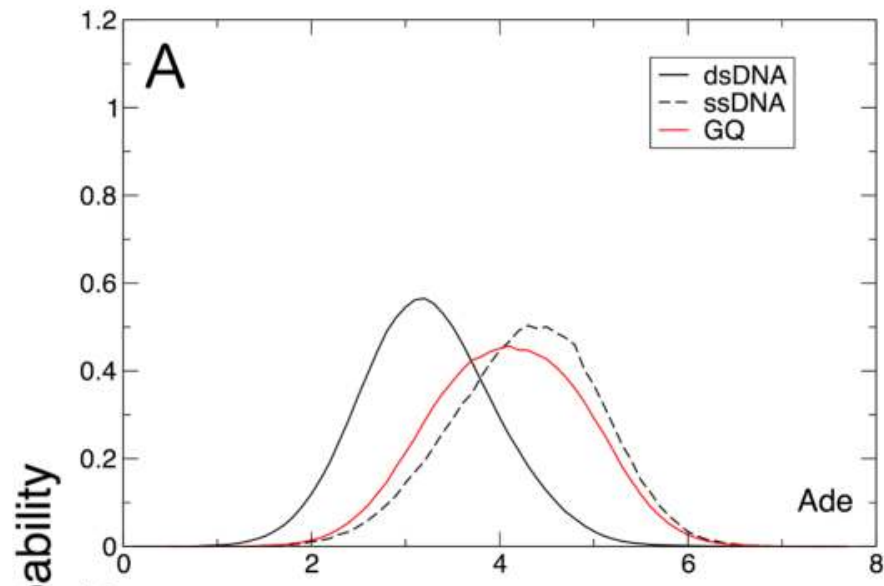

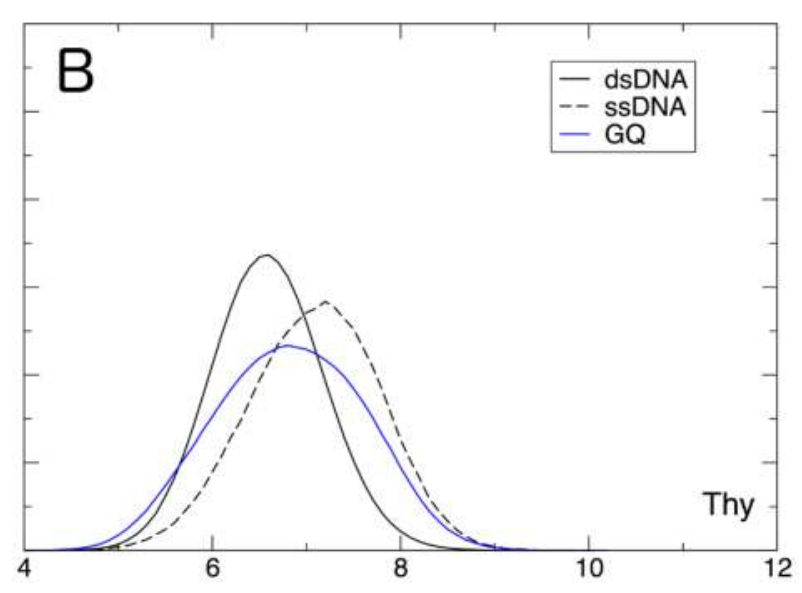

은
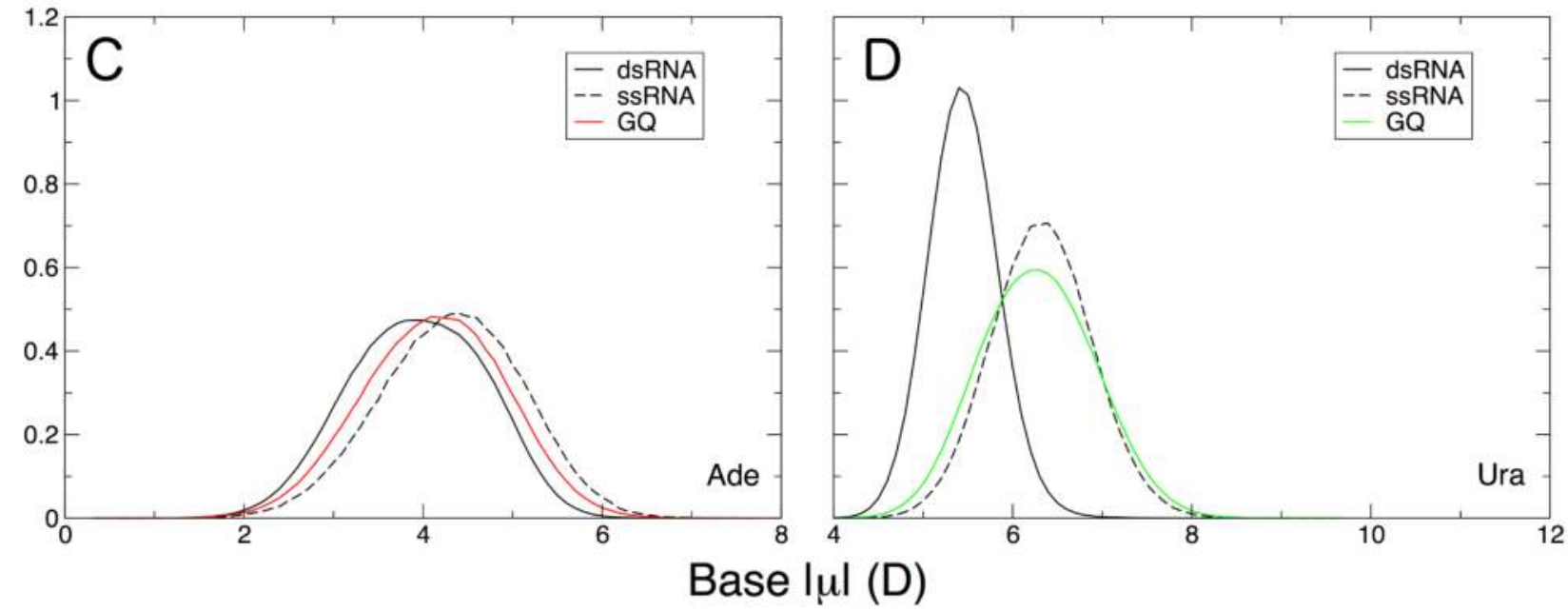

JAL (2020) Nucleic Acids Res. 48 (2): 561-575. 


\section{RNA Folding: gc(UUCG)gc Tetraloop}
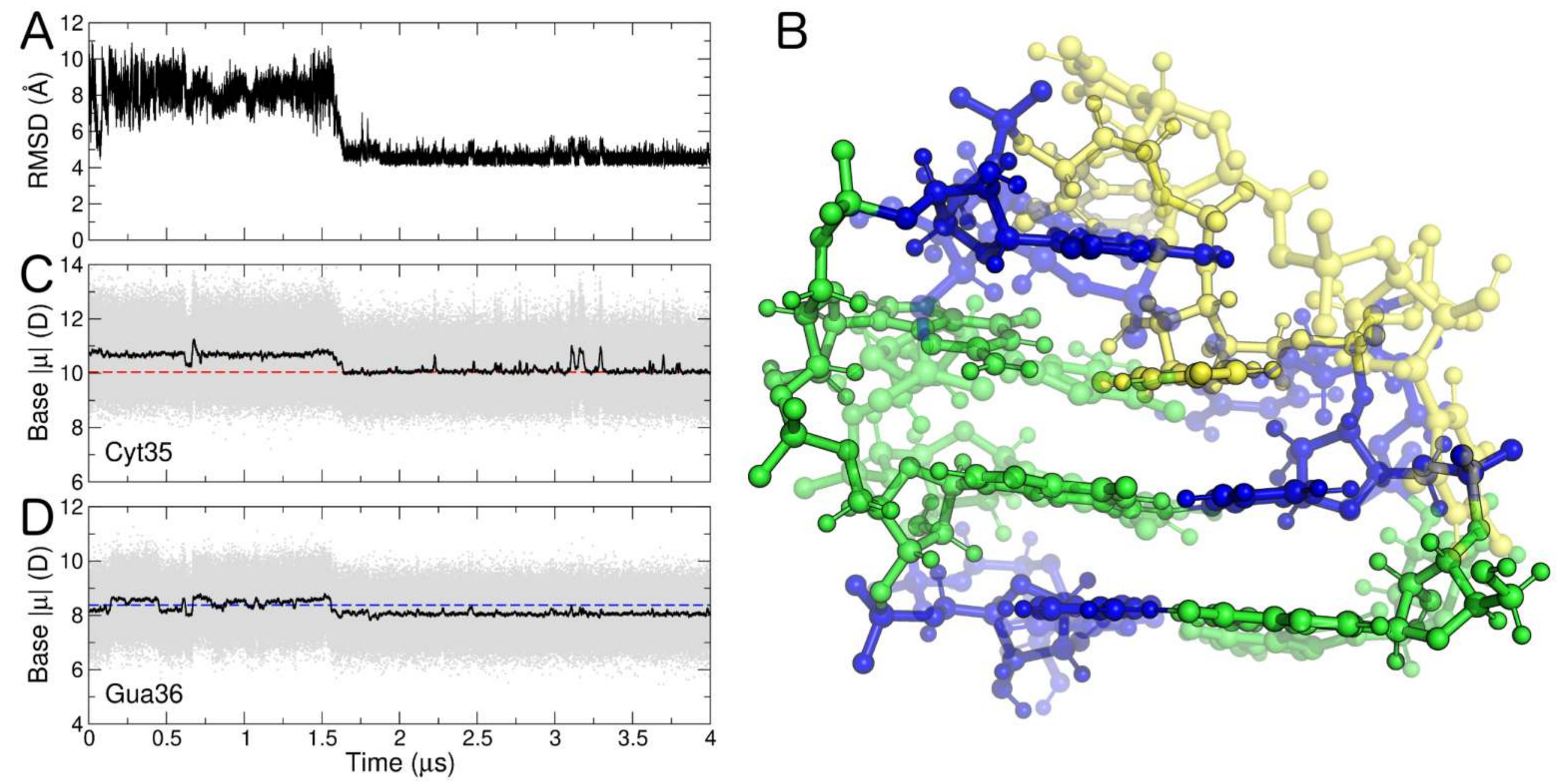


\section{Conclusions}

- Drude-2017 force field accurately models a wide range of nucleic acid structures, improvement over Drude-2013 in base stacking and conformational energetics

- Explicit electronic polarization improves $\mathrm{K}^{+}$retention in GQs

- Coordination of $\mathrm{K}^{+}$from bulk solution to open tetrad faces is a common feature but varies in affinity

- Base dipole moments in GQ stems are sensitive to $\mathrm{K}^{+}$ coordination

- RNA base dipole moments in stems and loops vary as a function of environment and folding state 


\section{Acknowledgments}

MacKerell Lab @ UMB

Alex MacKerell

Jing Huang

Alexey Savelyev

NIH)

National Institutes of Health

Turning Discovery Into Health

F32GM109632

R35GM133754

Health Resources in Action Advancing Public Health and Medical Research

Thomas F. and Kate Miller Jeffress Memorial Trust

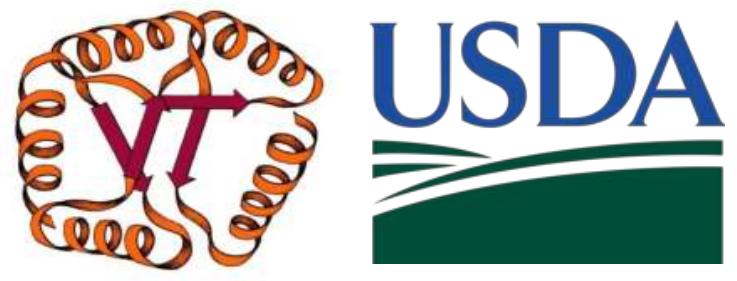

Lemkul Lab @ VT

Alexa Salsbury Darcy Davidson

Brian Ratnasinghe Julia Montgomery

Tanner Dean Alexsandra Corrigan

Jesse Janoski Joshua Kraus

Danielle Porier Karlie Wysong

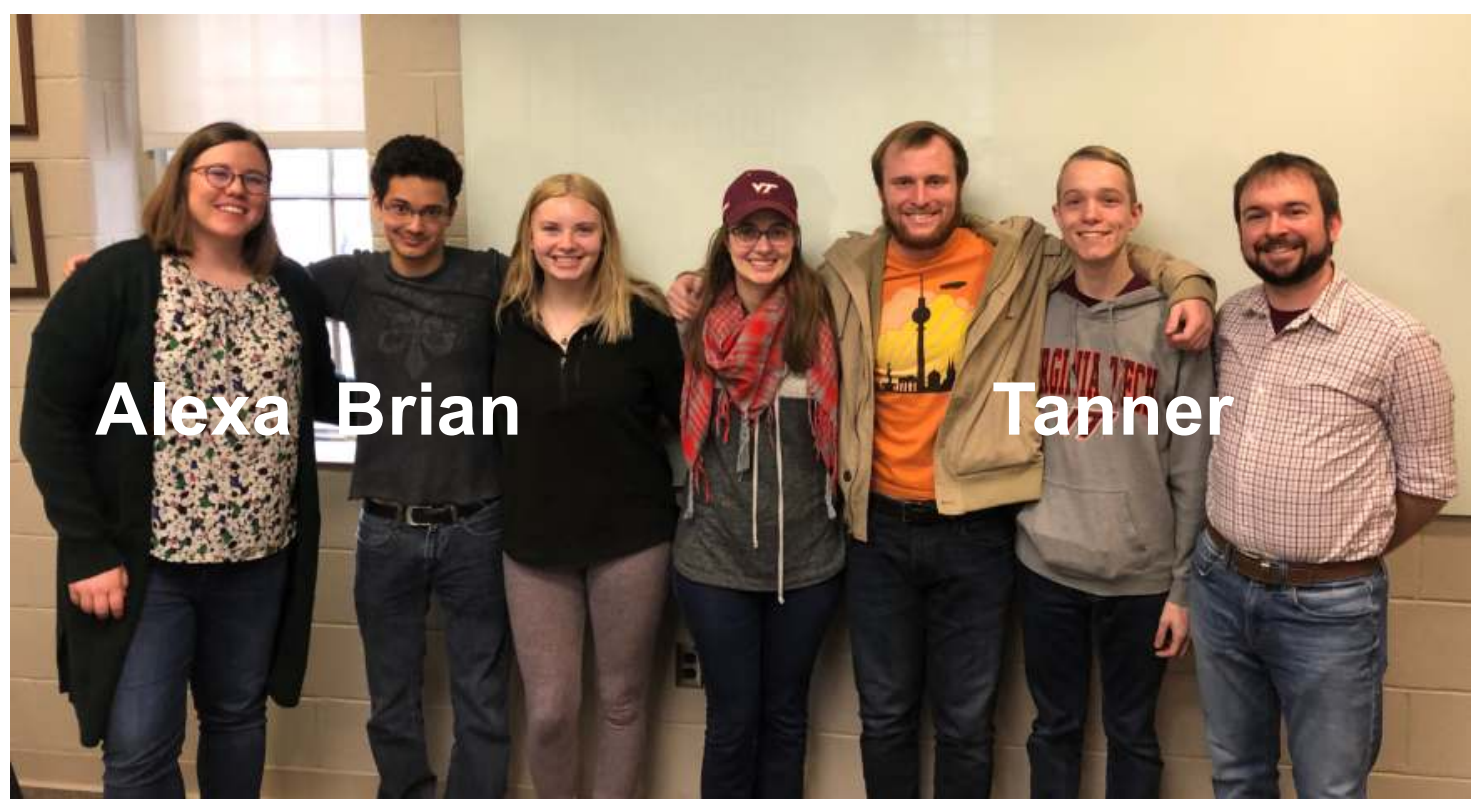

